\title{
STRUCTURE-ACTIVITY RELATIONSHIPS AND SURFACE IMMOBILIZATION OF POLYCATIONIC ANTIMICROBIALS
}

\author{
Mohamad Widodo, ${ }^{1}$ Sophie Anggitta Raharjani ${ }^{2}$ \\ ${ }^{1}$ Department of Textile Chemistry, Politeknik STTT Bandung \\ Jl. Jakarta No. 31, Bandung \\ E-mail: mwidodo@stttekstil.ac.id, ${ }^{1}$ anggitta.raharjani@gmail.com ${ }^{2}$ \\ Tanggal diterima: 9 November 2019, direvisi: 24 Juni 2020, disetujui terbit: 25 Juni 2020
}

\begin{abstract}
Antimicrobial agents have been the subject of scientific interest for the last few decades. However, the emergence of a novel coronavirus and pandemic that ensued has brought a new sense of urgency to the field of antibacterial research. The most urgent needs to mitigate the pandemic are self-disinfecting health equipment and antimicrobial protective equipment such as gowns for healthcare workers and face masks for the general public. At a time of high demand for antimicrobial products, understanding the mechanisms involved in antimicrobial polymers will be a benefit. In this review, the definition of antimicrobials and their classification according to the mode of action, as well as their chemical structure, were explained and used to build the fundamental understanding about antimicrobials and the working principles behind their action. The discussion continued with factors that affect the antimicrobial activity, which is the focus of the review. The first part of the review deals with free antimicrobial polymers in solution. The effect of molecular weight, counterions, spacer length and alkyl chain to the efficacy of antimicrobial polymers are highlighted and discussed at length. Focus in the second part shifts towards surfaceimmobilized antimicrobial polymers and their methods of immobilization.
\end{abstract}

Keywords: polymeric antimicrobial, antimicrobial structure, surface immobilization

\section{INTRODUCTION}

Contamination by microorganisms is of great concern in a variety of areas, such as medical devices, healthcare products, water purification systems, hospitals, dental office equipments, food packaging and storage, household sanitation, and still many more. ${ }^{1-3}$ Bacterial contamination on permanent catheters or implants, for example, can be a major problem. The use of long-term catheters can lead to serious implant-associated infections. In fact, medical implants account for nearly one-half of all nosocomial infections or healthcare-associated infections. ${ }^{4}$ Resolutions of these infections usually require removal of the implant. Because the success of the treatment in these cases is poor, the emphasis has been shifted and placed on ways to prevent catheter-related infections, ${ }^{1}$ which in most cases means some kind of antimicrobial pre-treatment. In the United States, approximately 2 million nosocomial infections cost nearly $\$ 11$ billion annually.

The food processing industry in the US accounts for nearly $26 \%$ of worldwide food processing output. ${ }^{5}$ There are more than 17,000 food-manufacturing factories around the US. During storage and distribution, food products undergo numerous physical, chemical, and microbial changes, which may lead to spoilage of foods.
Stricter requirements regarding consumer health and safety, among other factors, have created an everincreasing demand for innovation in food packaging. These are particularly important in the area of fresh and extended shelf-life foods. In this regard, antimicrobial packaging has been identified as one of the promising approaches toward the so-called active-packaging system. ${ }^{6,7}$

The rate of cross-contamination of the pathogen in hospitals is higher than that in any other places because they house a large number of people who are in various conditions of illness from many different types of diseases. The transmission takes place airborne and, more importantly, via the hands of healthcare workers, who are responsible for most of the nosocomial infection cases ${ }^{8}$. This has created a critical problem affecting the quality of healthcare. Preventive measures, including handwashing and the use of an antimicrobial agent, have been considered vital to combat hospital-related infections.

In medical textiles and protective clothing and textiles, the problems with contamination by microorganisms are even more crucial. Some of the examples of medical textiles include babies' diapers, wipes, adult sanitary and incontinence products, as well as operating gowns and drapes, and wound dressings. Included in the second category are personal protective clothing and masks. In the wake 
of the recent coronavirus outbreak, the exploration of antimicrobial agents for protective equipment has a new sense of urgency.

A string of pneumonic cases was first reported in December 2019 by the Wuhan Municipal Health Commission of China as a novel coronavirus. Three months after the report, on March $11^{\text {th }}$, the WHO announced COVID-19 as a pandemic. ${ }^{9}$ Evidence shows the most probable mode of transmission to be through direct contact with an infected person and the exchange of respiratory droplets ${ }^{10}$ produced when an infected person coughs, sneezes, or breathes. ${ }^{11}$ A cure or a vaccine for this virus has yet to be found at the time of this writing. Thus, preventing the spread of the infection has been front and center in the mitigation of this novel virus. Proper upkeep of personal hygiene and the use of effective protective clothing are enforced to minimize the spread of the disease both in hospitals and for the general public. The WHO strongly advises frequent handwashing for everyone and, while previously controversial, ${ }^{12}$ wearing face masks in public places are now also encouraged for everyone by the WHO. ${ }^{11}$ However, protective equipment such as gloves, masks, and medical gowns can also be a source of infection when handled poorly. The virus SARS-CoV of 2003 SARS outbreak showed a survival time of up to 2 days on a disposable gown and 24 hours on cotton gown. ${ }^{13}$ Taking into account the similarity of the current novel coronavirus with the previous type, it is most likely that the current SARS-CoV-2 can also have a similar survival time on textile surfaces. The use of antimicrobial polymers can reduce the survival time of viruses by rendering them uninfectionable upon contact.

In the past, a great number of studies have been done on antimicrobial agents since. Figure 1 shows the search result from Scifinder for studies on "antimicrobial or antibacterial" published within the first two decades since that period. The number of publications, which reflects the level of scientific activity as well as interest in the area, is growing exponentially. Consequently, that also strongly suggests that new developments are still arriving on the scene and maybe even heightened, which include new chemicals, more efficient routes of synthesis, novel approaches in their applications to a wider variety of materials, and new characterization methods. Recently there has been a great interest in the development of polymeric antimicrobial or antimicrobial polymers. Recent reviews dealing extensively with this topic are that of Kenawy, Worley \& Broughton's, ${ }^{1}$ Tashiro's, ${ }^{14}$ Muñoz-Bonilla, and Fernández-García's, ${ }^{15}$ Siedenbiedel and Tiller's, ${ }^{16}$ and Santos et al's. ${ }^{17}$ They focused on the synthesis and preparation of polymeric antimicrobials, especially those based on quaternary onium compounds. A brief survey on their immobilization on surfaces, however, was also given. Lately, much interest has been given to the development of a non-leaching self-sterilizing surface. Successful covalent attachment of polymeric antimicrobial materials on glass, ${ }^{18-20}$ polymer, ${ }^{21-28}$ paper, ${ }^{20}$ and metal $^{29}$ have been reported recently. One of the early works in this area is the study by Isquith et al. ${ }^{30,31}$ in the 1970's who used alkoxysilane quaternary ammonium compound to produce durable antimicrobial activity on glass surfaces and cotton cloth.

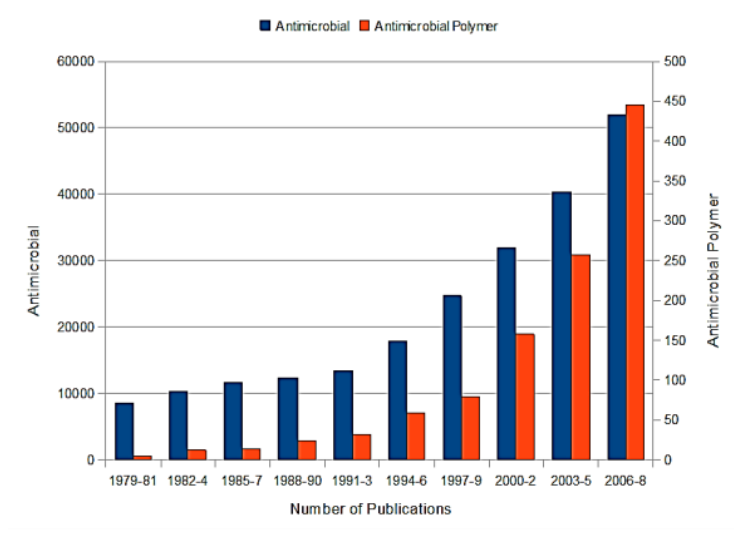

Figure 1. The number of journal publications on antimicrobials published between 19782008.

In light of the ongoing pandemic, an understanding of antimicrobial agents is needed. This review attempts to establish an overview of polymeric and surface-bound antimicrobial agents, the factors affecting their efficacy, and the underlying mechanisms of action against microbes. The bulk of the review will be focused on the surface-activity of antimicrobials against bacterial cells. Considering the similarities of bacterial cell surface and the surface of the enveloped viruses such as influenza ${ }^{32}$ and coronaviruses, ${ }^{33}$ an understanding of the above topics may provide insight into the use and production of much-needed antibacterial and antiviral products.

\section{Definitions of Antimicrobial Agents}

Microbe is a common term for microorganism. The term microorganism itself has several definitions, varying in the degree of inclusion to non-living beings comprised of the building blocks of life such us protein and genetic information. Oxford Dictionary of Biochemistry and Molecular Biology" ${ }^{34}$ defined "microorganism" as "any noncellular or unicellular (including colonial) organism, most of which are too small to be seen with the unaided eye. Microorganisms comprise bacteria (including cyanobacteria), lichens, microfungi, protozoa, rickettsiae, virinos, viroids, and viruses, and also some algae; all prokaryotes are 
included". This is the definition that is used throughout this paper.

Several terms on the use of agents having the capability to handle microorganisms have been used in the literature. Sometimes they are used interchangeably and inconsistently, which may confuse the readers. It is, therefore, useful to define these terms before going any further.

The term of antimicrobial agents has been used in the literature to refer to and defined as materials that kill or inhibit the growth of pathogenic microorganisms. ${ }^{1,35}$ The term is indeed a generic one. According to "Oxford Dictionary of Biochemistry and Molecular Biology", ${ }^{34}$ the term antimicrobial is "describing a drug, antibiotic agent, physical process, radiation, etc. that is inimical to microbes".

Antimicrobials can be divided into two main categories: biocides and biostats. A biocide is a chemical that kills microorganisms, while a biostat is a chemical that inhibits the growth of microorganisms. ${ }^{34}$ While biocide must be registered with the EPA as a pesticide and labeled with a public health claim, a biostat, however, does not need to be registered, nor does it require special labeling. ${ }^{36}$

The term "biocide" has been widely used in the literature, especially when authors need to emphasize the killing power of the agents they are referring to. While it may be impressive to the reader, it could be misleading, especially when the agents are not really meant to kill everything. Technically, the term refers to any chemical substance that kills living cells or organisms ${ }^{36}$, both pathogenic and nonpathogenic, which does not limit it to micro only. It is a generic term, which comprises, among others, microbicides, insecticides, herbicides, and rodenticides. ${ }^{36}$ On the other hand, microbicide is a generic term that includes bactericides, fungicides, and algicides, to name a few. The same distinction should be used for "biostat" and "microbiostat".

Although a distinction is often made between "static" and "cidal" compounds, the division is by no means clear-cut. Many compounds are static at low concentrations and cidal at higher concentrations, while the effect may also depend on the condition of the culture. According to Franklin and Snow, ${ }^{37}$ at low concentrations, a certain biochemical function associated with the microbial membrane may be inhibited but may not necessarily lead to cell death, hence antimicrobial is biostatic.

Antibiotics are natural, semi- or whollysynthetic antimicrobial agents that are able to selectively destroy or inhibit the growth of other microorganisms at low concentrations. ${ }^{34,36,38}$ Some of the common examples are penicillin, neomycin, gentamycin, and quinolone. They are used mostly as chemotherapeutic agents to treat infectious diseases and do not normally find applications in technical systems. However, successful insolubilizations of antibiotics have been reported on cellulose, ${ }^{39}$ polyamide (Nylon 6), ${ }^{40}$ poly(methyl methacrylateco-maleic anhydride), and poly(styrene-co-maleic anhydride). ${ }^{41,42}$ A cautionary note must be given here that antibiotics are not able to kill viruses.

\section{Classification of Antimicrobial Agents}

Antimicrobial agents can be classified and organized based on their chemical structure and parent compound. In this regard, the work by Paulus $^{36}$ deserves particular attention and appreciation. It is a directory of antimicrobial agents with quite extensive examples provided in each of the categories. Although it is intended for the protection of materials, the same principles for understanding structure-property relationship apply to other areas as well. Another source that is also worthy of looking at is that of Moore and Payne's, ${ }^{43}$ in which numerous types of antimicrobial agents are discussed systematically based on their chemical structure with extensive references to the original works.

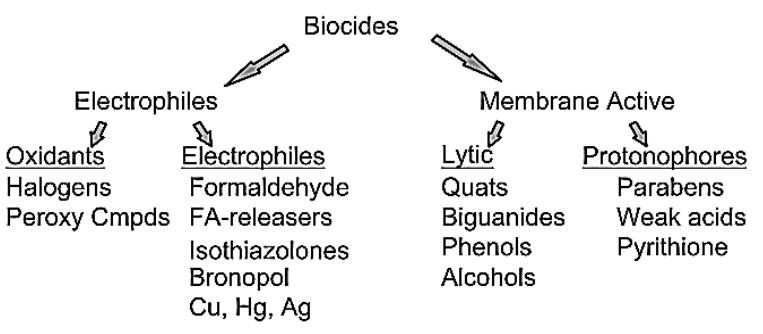

Figure 2. Biocide mechanisms of action. ${ }^{44}$

Antimicrobial agents may also be divided based on their mechanisms of action. Paulus ${ }^{36}$ divided them into two broad categories, i.e. those that are electrophilically active and membraneactive. Chapman ${ }^{44}$ divided each of the groups further into two sub-categories, which makes four broad categories of antimicrobials and includes oxidants, electrophiles, lytic, and protonophores (Figure 2). The oxidants include rapid speed killing agents such as chlorine ${ }^{45-50}$ and peroxides ${ }^{51-54}$ that work directly via radical-mediated reactions to oxidize organic material. The electrophilic agents include inorganic ions such as silver, copper, and mercury, and organic biocides such as formaldehyde and isothiazolones. The antimicrobial effectiveness of these substances results from the fact that they are in search of substrates with electron density rich centers such as nucleophilic components of the microbial cell surface (e.g. amino, thiol, and amide groups of amino acids and proteins). The corresponding result of this contact is an electrophilic addition or substitution that leads to the inactivation of enzymes. Cationic membrane-active biocides such as chlorhexidine and quaternary ammonium compounds and alcohols such as phenoxyethanol 
destabilize membranes leading to rapid cell lysis. Weak acids such as sorbic and benzoic acids, which belongs to protonophores, interfere with the ability of the cell membrane to maintain a proper $\mathrm{pH}$ balance, resulting in acidification of the cell interior and widespread disruption of metabolism.

A more general classification of antimicrobial products is based on their mode of actions. They can function through one of two different mechanisms, known as leaching and non-leaching. The former operates by slowly releasing an active component from a chemical reservoir on either the surface or interior of a substrate. It is considered very effective against microbes on the surface and in the surrounding environment, but the effectiveness will decrease with time as the reservoir is depleted. The halamine-based antimicrobial developed by Sun and co-workers ${ }^{55}$ is one good example of this type of antimicrobial and deserves special attention because it demonstrates the ingenuity in circumventing the limitations inherent in the conventional system. With this novel approach, the once depleted active component, which in this case is chlorine, can be recharged by regular laundry exposure to chlorine bleach, and hence it represents a regenerable system. However, in textile applications, the use of high concentrations of chloramine may cause some problems, which include yellowing with heat (for example, ironing) and cellulose fiber damage, especially significant strength loss, generated by the formation of oxy- and hydrocellulose ${ }^{56}$. In the nonleaching type antimicrobial products, the active component remains at the surface so that their effectiveness, despite permanent, is limited only upon contact and adsorption.

\section{Factors Affecting the Efficacy and Activity of Antimicrobial Polymers}

Ideally, any given antimicrobial polymer should possess the following characteristics. ${ }^{1,56}$ (1) easily and inexpensively synthesized, (2) stable in long-term usage and storage at the temperature of its intended application, (3) not soluble in water for water-disinfection application, (4) does not decompose to and/or emit toxic products, (5) should not be toxic or irritating to those who are handling it, (6) can be regenerated upon loss of activity, (7) no adverse effect on the substrate it is applied to, and (8) effective against a broad spectrum of pathogenic microorganisms in (9) brief times of contact.

Many factors can affect the performance of antimicrobial agents. According to Russel, ${ }^{57}$ the activity of microbicides depends on the external physical environment, the nature, structure, composition, and condition of the organism; and the ability of the organism to degrade or inactivate the particular substance that converts it to an inactive form (resistance). These are the external as opposed to the internal factors, which are inherent in the antimicrobial polymer and are identified by Kenawy et al. ${ }^{1}$ as molecular weight, spacer length between the active site and polymer, hydrophilic-lipophilic balance (HLB), and the nature of counterion (for "onium"-based antimicrobials). Additionally, the location of the active component relative to the polymer backbone (in-chain or side chain) is also important.

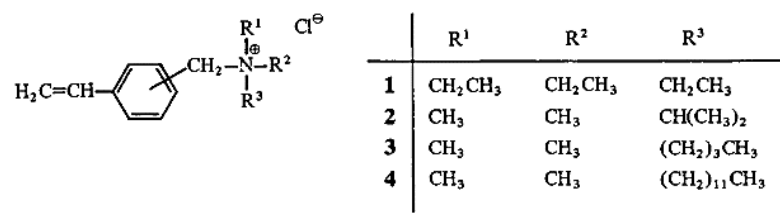

Figure 3. Poly [trialkyl (vinylbenzyl) ammonium chloride]. ${ }^{58,59}$

\subsection{Molecular weight}

Molecular weight obviously has a significant influence on the efficacy of antimicrobial polymer. The general observation and most significant finding from early studies on molecular weight dependence of antimicrobial activity is that polymeric antimicrobials are much more active than their corresponding monomers. The minimum inhibitory concentration (MIC) of poly[trialkyl(vinylbenzyl) ammonium chloride] (Figure 3), as shown by Ikeda and co-workers, ${ }^{58,59}$ for example, is much lower than its monomeric species by two-orders of magnitude. Further investigation by Ikeda and co-workers ${ }^{60}$ showed not only marked as a dependence of activity on molecular weight but also the existence of an optimum region (Figure 4), which in this particular example is between $5 \times 10^{4}$ and $10 \times 10^{4} \mathrm{Da}$. Later studies, including those with different systems such as quaternary phosphonium salts (Figure 5) and chitosan, show similar trends in which antimicrobial activity increases with molecular weight. ${ }^{61-64}$

The observed molecular weight dependence of the antibacterial activity in the above-cited works may be interpreted based on the contribution of the polymers to each of the elementary steps in their mode of action. The generally accepted mechanism of action for cationic microbicides in killing bacteria involves the following processes: ${ }^{14,63,65}$

(1) Adsorption onto the bacterial cell surface

(2) Diffusion through the cell wall

(3) Binding to the cytoplasmic membrane

(4) Disruption of the cytoplasmic membrane.

The latter leads to the release of cytoplasmic constituents such as $\mathrm{K}+$ ions, RNA and DNA, which will eventually lead to the cell death.

The bacterial cell surface is negatively charged at physiological $\mathrm{pH}$, whereas cationic microbicides are positively charged. The microbicides are adsorbed onto the surface of the cell wall by electrostatic interaction. Consequently, polycations are adsorbed onto the negatively charged cell surfaces to a greater extent than monomeric 
cations because of the much higher charge density carried by them. The adsorption is also becoming more favorable for the binding of the polycation to the cytoplasmic membrane of bacterial cells, since there are many negatively charged species present in the cytoplasmic membrane, such as acidic phospholipid and some membrane proteins. The enhanced adsorption at the two levels of activity (steps 1 and 3) generates higher stress to the cell membrane that induces more of their disruption, which eventually results in a higher number of cell death. While processes 1,3 , and 4 are expected to enhance with higher molecular weight, it should be noted that process two is depressed, in which diffusion of still higher molecular weight is hindered due to size effect. That explains the sharp decrease in activity at much higher molecular weight (Figure $5)$.

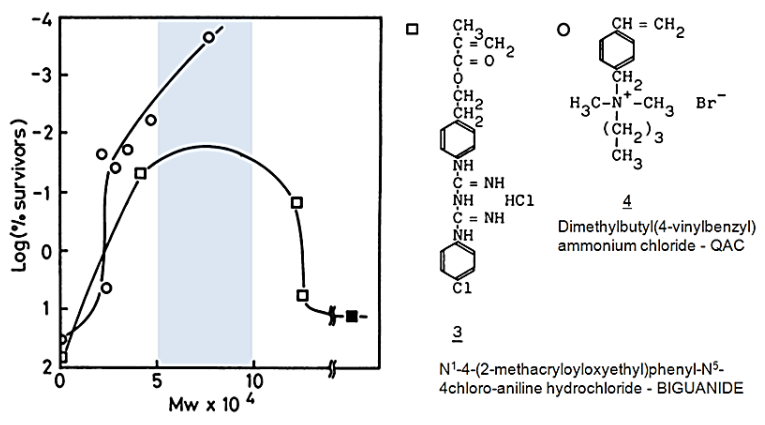

Figure 4. Effect of MW on antibacterial activity against $S$. aureus. $\square$ poly $3,23 \mu \mathrm{M}$; $\bigcirc$ poly $4,2.0 \mu \mu \mathrm{M}$; plot for microgel of poly $3 .{ }^{60}$
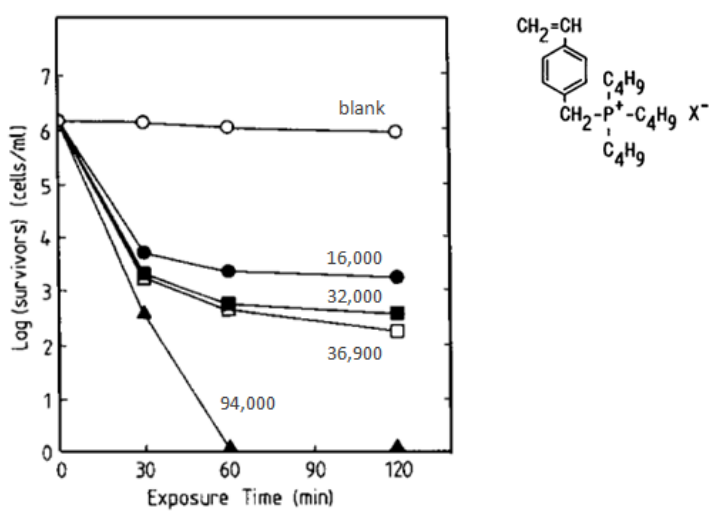

Figure 5. Plots of log (survivors) versus exposure time of $S$. aureus to tributyl(4vinylbenzyl) phosphonium chloride $(2.8$ $\mu \mu \mathrm{M})$ of various $\mathrm{MW}$ : $\mathrm{O}$ blank; $\Delta 94,000$; $\square$ 36,900; $\mathbf{\square 2} 2,000 ; \bullet 16,000 . \mathrm{X}=\mathrm{Cl}$.
Quite interestingly, on the contrary to the above finding, Panarin and co-workers ${ }^{66}$ reported that antimicrobial activity is independent of molecular weight within the molecular weight range investigated (Table 1). They used water-soluble copolymers of $\mathrm{N}$-vinylpyrrolidone with aminoalkyl methacrylate and their quaternary ammonium salts (Figure 6) against Streptococcus aureus, a Grampositive bacteria. According to Chen et al. ${ }^{67}$ and Kenawy et al. ${ }^{1}$ the discrepancy may be explained by taking into account the bacteria structure, which may be divided into two classes, Gram-positive and Gram-negative. Gram-positive bacteria tend to have a loose cell wall, while Gram-negative bacteria have an outer membrane structure in the cell wall providing an additional barrier to foreign molecules. The type of microorganisms is also important, because different organisms show varying responses to biocides. ${ }^{68(\mathrm{pp} \mathrm{111-115)}}$ It is also true that the type of microorganism may significantly affect the mechanism of action and hence the performance of antimicrobial agents. ${ }^{64,69}$ However, these cannot be the complete explanation, since the two differently reported behaviors actually came from the same class and type of bacteria, S. aureus.

Molecular weight dependence of antimicrobial activity was also found in dendrimer, in which the relationship assumes an interesting parabolic form. Dendrimers are novel, highly branched 3-dimensional macromolecules that emanate from a central core (Figure 7). They have a very compact structure, and many end groups at their outer surface, which can be functionalized for many different purposes, and thus have attracted attention as well as created an upsurge of interest, especially from the material science community. Chen and coworkers ${ }^{67}$ synthesized quaternary ammoniumfunctionalized poly-(propyleneimine) dendrimers for use as an antimicrobial biocide. They used a series of dendrimers with the same length of alkyl chain but a different generation or number of monomer layers. From Figure 7, it is obvious that a dendrimer with a higher generation would have a higher number of quaternary groups so that it is expected to be more potent because its interaction with cell surfaces is more enhanced, which gives rise to more enhanced adsorption. However, when permeability through the cell wall and the cell membrane is taken into account, the trend should be the opposite, in which larger molecules would experience more difficulty in penetrating the barriers. 
Table 1. Effect of molecular weight (denoted by intrinsic viscosity) on antimicrobial activity of cationic polyelectrolyte. ${ }^{66}$

\begin{tabular}{|c|c|c|c|}
\hline Copolyner & $\begin{array}{l}\text { 1onogen ic } \\
\text { groups, mol-8 }\end{array}$ & {$[n]^{a}, \mathrm{~d} 1 \cdot \mathrm{g}^{-1}$} & $\mathrm{mic}^{\mathrm{b}}, \mu \mathrm{g} / \mathrm{m} 1$ \\
\hline $2 b$ & $\begin{array}{l}18.8 \\
18.0 \\
18.8 \\
18.4\end{array}$ & $\begin{array}{l}1.12 \\
0.97 \\
0.84 \\
0.73\end{array}$ & $\begin{array}{l}300 \\
300 \\
300 \\
300\end{array}$ \\
\hline 18 & $\begin{array}{l}23.5 \\
24.7 \\
24.4 \\
25.2\end{array}$ & $\begin{array}{l}0.96 \\
0.89 \\
0.78 \\
0.50\end{array}$ & $\begin{array}{l}300 \\
300 \\
300 \\
300\end{array}$ \\
\hline
\end{tabular}

$a_{0.5} \mathrm{M} \mathrm{KCl}, 25^{\circ} \mathrm{C} .{ }^{\mathrm{b}}$ Based on the test solution of Staphylococcus aureus $209 \mathrm{p}$ strain.

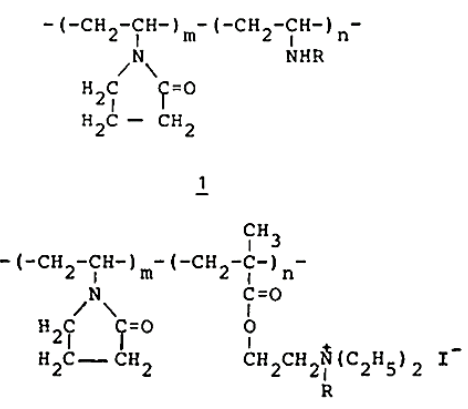

$\underline{2}$
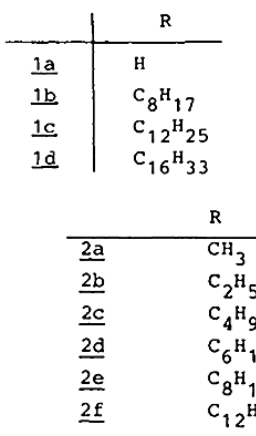

(a)

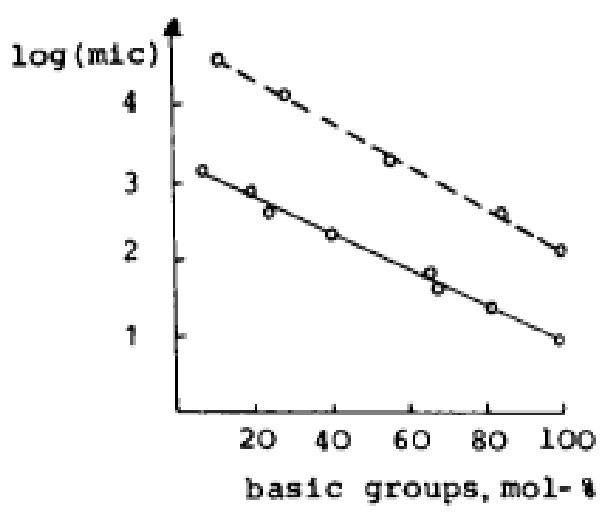

(b)

Figure 6. Copolymer N-vinylpyrrolidone with aminoalkyl and methacrylate. ${ }^{66}$

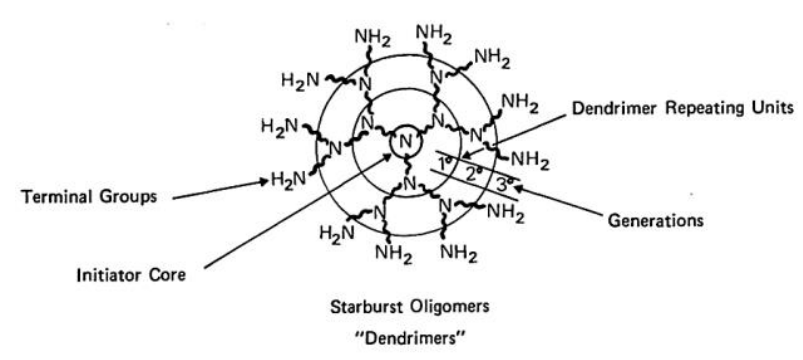

Figure 7. Schematic representation of a dendrimer structure and architecture ${ }^{70}$
Figure 8a shows how the combination of the two opposing effects affects the antimicrobial activity of dendritic biocide. As generation increases, the size of the molecule and the number of functional groups grow exponentially. The antimicrobial activity decreases through a minimum (that is maximum relative bioluminescence) and then increases as electrostatic interaction overwhelms the size effect. The observation is quite the opposite to the conventional polymeric biocides, in which antimicrobial activity of smaller molecules increases monotonically with molecular weight to a maximum and then decreases sharply at the higher molecular weight. In this case (conventional polymeric biocides), electrostatic interaction is predominant in the low molecular weight regime. As the molecules grow larger, the size effect takes over.
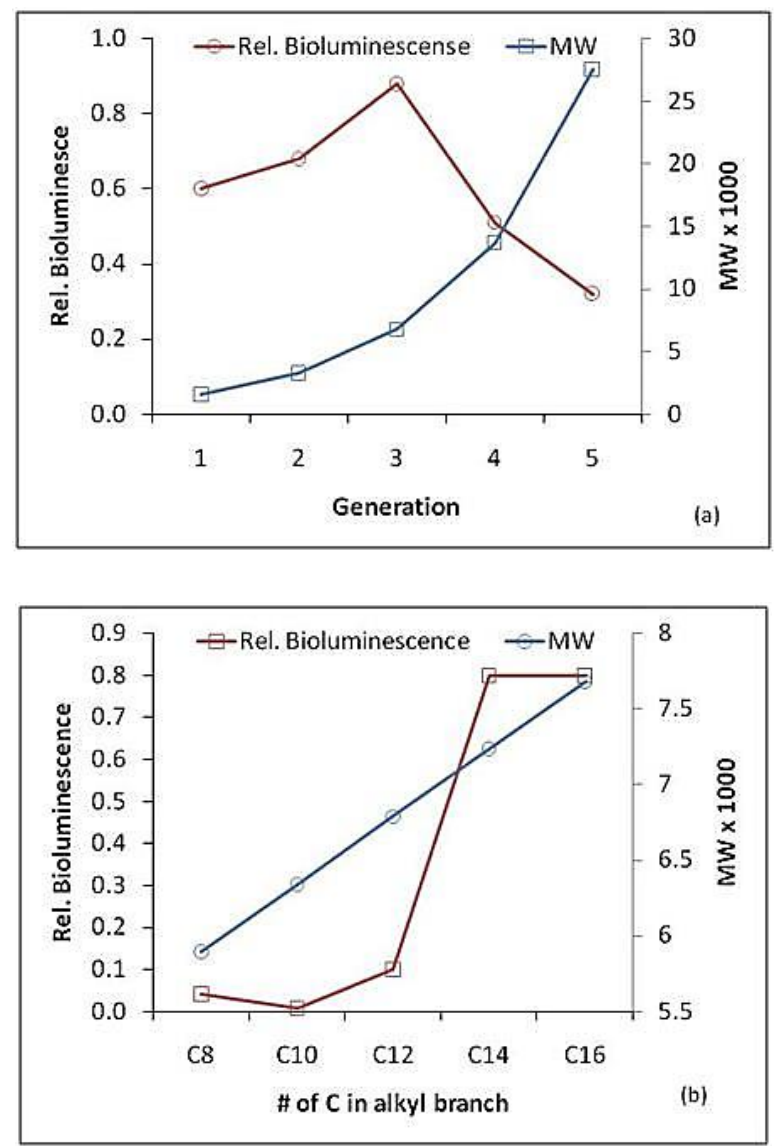

Figure 8. Effect of generation number (MW) (a) and chain length (b) of quaternary ammoniumfunctionalized dendrimer antimicrobial activity (Escherichia coli) (adapted from Ref.). ${ }^{67}$ 


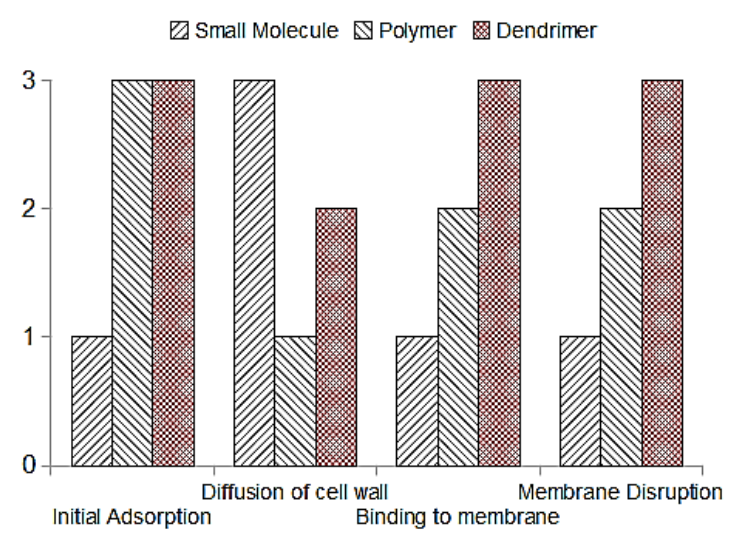

Figure 9. Comparison among small molecule biocides, polymer biocides, and dendrimer biocides in terms of their interactions with bacteria. 1 = low/weak, 2 = medium, $3=$ high/strong. ${ }^{67}$

Apparently, with dendritic biocides, permeation occurs predominantly for low molecular weight biocides, which is gradually suppressed, as dendrimer size grows larger with generation number. However, the fact that larger molecules with more functional groups are more potent implies that charge density plays a more important role than permeation. That explains the difference in the nature of the relationship between polymeric biocides and bacteria on one side and dendritic biocide and bacteria on the other side. A fascinating comparison of dendrimer, polymer, and monomer biocides, based mostly on the analysis of their size and mode of interactions with bacteria, is qualitatively summarized by Chen et $\mathrm{al}^{67}$ and is presented in Figure 9.

In summary, the antimicrobial activity of polymeric biocides and dendritic biocides is affected by molecular weight, especially when the latter is accompanied by an increase in charge density of the polymer. The two classes of biocides respond differently to the change of molecular weight. Due to its higher charge density on its surface, dendritic antimicrobials are generally more potent than polymeric and monomeric biocides.

\subsection{Counterions}

It was found that antibacterial activity is affected by the type of counter anion ${ }^{63,67,71,72}$ (Figure 10). The activity, according to the work reported by Kanazawa and co-workers ${ }^{61}$, is correlated very well with the solubility products of the polymers (KSP) or dissociation constant. The activity is high for those that dissociate more readily and become free ions, so that the active species, which is cation on the host polymer, is more readily available for the action. It is clear that KSP affects antibacterial activity. The order of activity in their study was $\mathrm{Cl}>$ $\mathrm{BF}_{4}>\mathrm{ClO} 4>\mathrm{PF}_{6}$.
Chen et al. ${ }^{67}$ found that biocides with bromide anion are more potent than those with chloride anion. Keszczynska et al., ${ }^{71}$ in their study to investigate the role of counterions in the interaction of cationic surfactants with model membranes, arrived at the same result; benzyltrimethylammonium (BTA) bromide-induced hemolysis was found slightly greater than that induced by BTA chlorides. The fact that it was only slightly greater supports the remark made by Chen et al. ${ }^{67}$ on their own results that the difference was not expected, as both ions are, in fact, tend to dissociate freely in the water.

In this context, Panarin et al. ${ }^{66}$ reported a linear dependence of the logarithm of MIC of $S$. aureus on the content of counterion in the copolymers they studied (Figure 6b). This relationship was construed as a proof for electrostatic interaction between polyelectrolyte and bacterial cell surface. They also pointed out that the nature of counterion between $\mathrm{Cl}-, \mathrm{Br}$ - and I- does not affect the activity level and linear dependence. Unfortunately, supporting data for the latter is nowhere to be found in their paper. It is very likely that the slight difference in the dissociating power between these ions, as mentioned above, is the reason why Panarin et al. did not observe any difference in antibacterial activity of their samples.

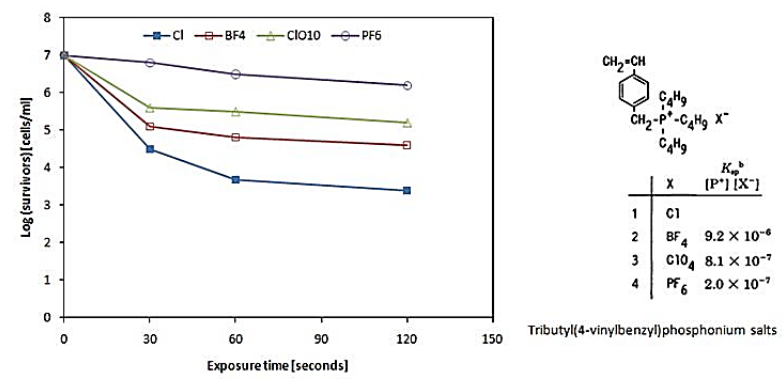

Figure 10. Effect of counterion composition to antimicrobial activity for tributyl(4vinylbenzyl) phosphonium salts at 2.8 $\mathrm{mM}$ against $S$. aureus, and its relationship with solubility product constant of polymer KSP. ${ }^{61}$

\subsection{Effect of Spacer Length and Alkyl Chain}

It is quite reasonable to assume that spacer length has an effect on the activity of antimicrobial polymer due to the change in conformation, which consequently affects the level as well as the mode of interaction with the cell membranes. A series of studies carried out by Kanazawa et al. ${ }^{62,63}$ showed that spacer length indeed affects the antimicrobial activity of polymeric biocides. In the case where phosphonium (or ammonium) salts are located in the main chain, the antibacterial activity increased with spacer length. This finding suggests that the long spacer is favorable for strong interaction with cytoplasmic membrane owing to the thrusting effect of the long alkyl chain inserted into the hydrophobic 
parts in the bilayer membranes of bacteria. Quite the opposite, the antibacterial activity of polymeric phosphonium salts decreased as side-chain length increased.

The explanation for this observation lies not on the size of the polymer coil because the polymers have nearly the same molecular size due to the approximately identical molecular weight and composition. To explain the contradicting behaviors, Kanazawa et al. ${ }^{73}$ proposed that both polymers might form aggregates in aqueous solution to a different extent and of different sizes depending upon the length of hydrophobic chains in the polymers. This aggregation results from the hydrophobic interactions that occur between hydrophobic chains, and somehow it is very likely that the interaction is more pronounced for polymers with side-chains. Those with longer side-chain would form aggregates large enough to be excluded at the cell walls of bacteria, resulting in the suppression of the activity. Further studies by the same group on the effect of morphology on the mode of action and antibacterial activity support the above proposition that antibacterial activity of cationic biocides could be affected by the state of aggregation. $^{74}$

Chen et al. also investigated the effect of hydrophobic chain length in dendritic biocides on biocidal activity and found a parabolic relationship, as shown in Figure 8b. This is a general phenomenon often observed in long-chain surface-active substances; the activity increases progressively with increasing chain length up to a critical point, beyond which the activity decreases. This behavior is called the cut-off effect and was observed in the antimicrobial activity of homologous series of quaternary ammonium salts for the first time more than 70 years ago. ${ }^{75}$ Dendritic-QAC biocides with C10 (ten carbon atoms) chains tend to be the most effective, followed by $\mathrm{C} 8$ and $\mathrm{C} 12$ chains. Chen et al. ${ }^{67}$ pointed out that this behavior may be attributed to (1) dual binding sites on the surface for which the relative binding affinities at each site differ for long and short alkyl substituents or (2) different aggregational behavior for long and short hydrophobic chains. Since the concentration used was much lower than the critical micelle concentration, they concluded the former as more plausible for dendrimer biocides. Nakagawa et al. ${ }^{76}$ immobilized on porous glass a series of low molecular weight quaternary ammonium salt (QAS) with different alkyl chain lengths and found similar parabolic relationship. Quite surprisingly, polymers of QAS behave differently. The results from different studies are presented in Table 2.

Ikeda et al. ${ }^{58}$ discovered that the activity of poly[trialkyl(vinylbenzyl) ammonium chloride] against $S$. aureus increased with the number of carbon atoms in the hydrophobic chain (tail) and reached the highest with the longest substituent, C12. A similar trend was also found in a more recent study by Nonaka et al. ${ }^{77}$ with a copolymer of $\mathrm{N}$ isopropylacrylamide with methacryloyloxyethyl trialkylphosphonium chlorides. Kanazawa et al., ${ }^{78}$ however, found the contrary. They observed the activity of polymeric phosphonium salts decreased with hydrophobicity and suggested that it could be interpreted based on the size of polymer assembly in solution. The critical micelle concentration of surfactants with the same hydrophilic groups decreases with the increase of the alkyl chain length. As a result, the aggregation number and micelle size should increase accordingly. For antimicrobial polymers, this would make the diffusion through the cell wall more difficult, resulting in lower antimicrobial activity. It is not clear why they should be different, but it was possibly due to the difference in critical micelle concentration of each of the polymers and the concentration used in each of the corresponding antimicrobial tests. By contrast, the activity of chemically similar low molecular weight model compounds used in the same study increased with hydrophobicity.

Much earlier on, Panarin et al. ${ }^{66}$ showed that the antimicrobial activity of polymers is independent of the length of the substituent. In contrast, for the monomers, it increases by several orders of magnitude when the alkyl chain length is increased from $\mathrm{C} 1$ to $\mathrm{C} 16$. They suggested that this is most probably due to conformational changes of the polymer because of hydrophobic interactions between alkyl substituent along the chain. The conformation is such that hydrophobic chains are inside the coil, whereas the ionogenic (QAC) groups are outside. When they come into contact with bacterial cells, they interact with the cell surface only electrostatically. Since the numbers of charges for the investigated macromolecules are equal, in the absence of hydrophobic interactions, their activities are also equal. It is interesting to note at this point that recently Lewis and Klibanov ${ }^{79}$ suggested how hydrophobic interaction may interfere with antimicrobial activity and stressed that the polymeric chains on substrate surface must be in the form of individual entities rather than entangled agglomerates to perform effectively.

Studies with cationic antimicrobial peptide $^{80,81}$ showed that agents with longer spacer exhibit higher activity than those with a shorter spacer. According to the authors, a longer spacer gives more flexibility and better penetration into the cell wall of bacteria. An effective antimicrobial must have a spacer long enough to span through the thickness of the cell wall and interact with the cytoplasmic membrane. Increasing the surface density of antimicrobial peptide does not improve the activity of antimicrobials with a short spacer. 


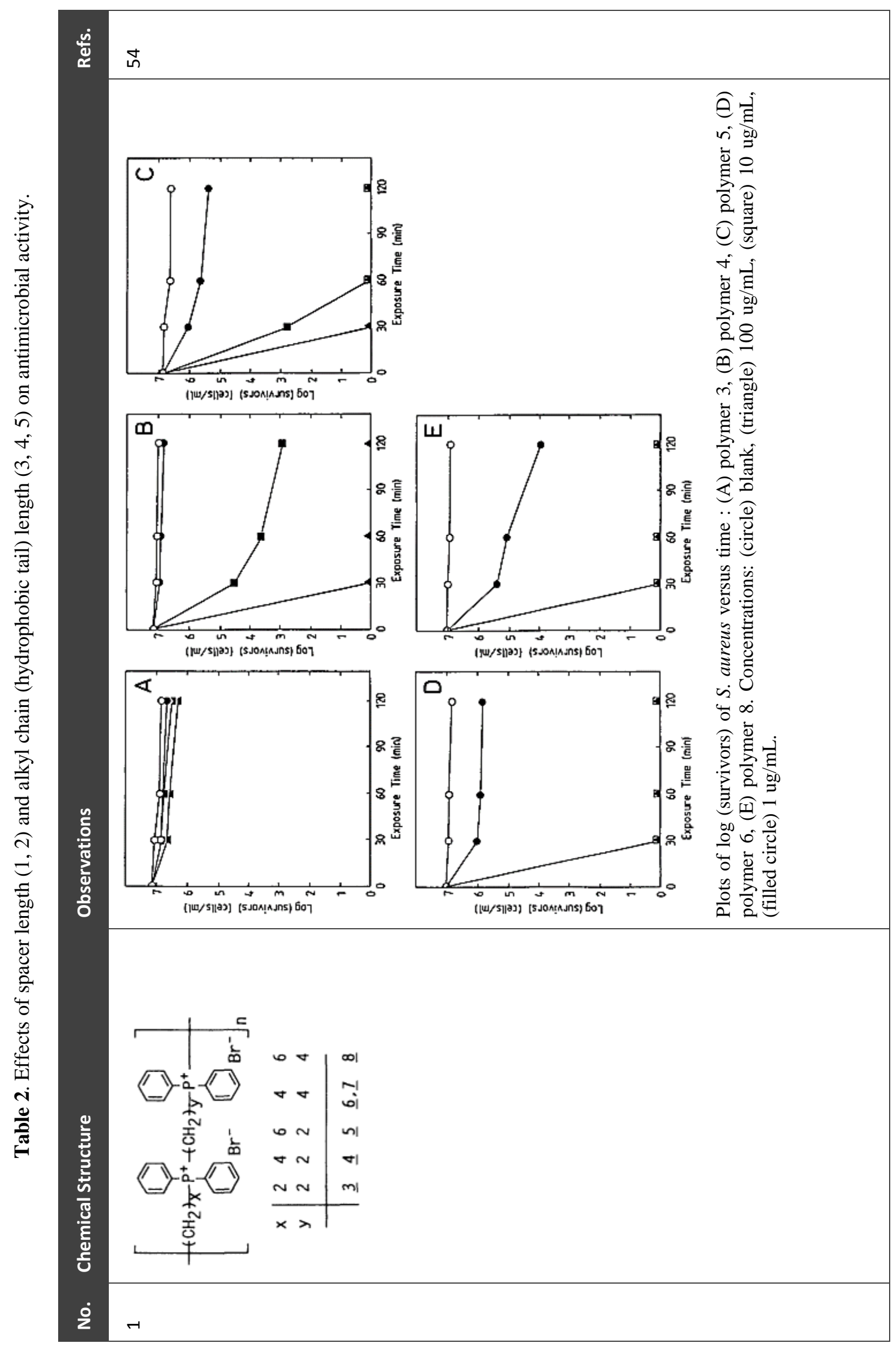




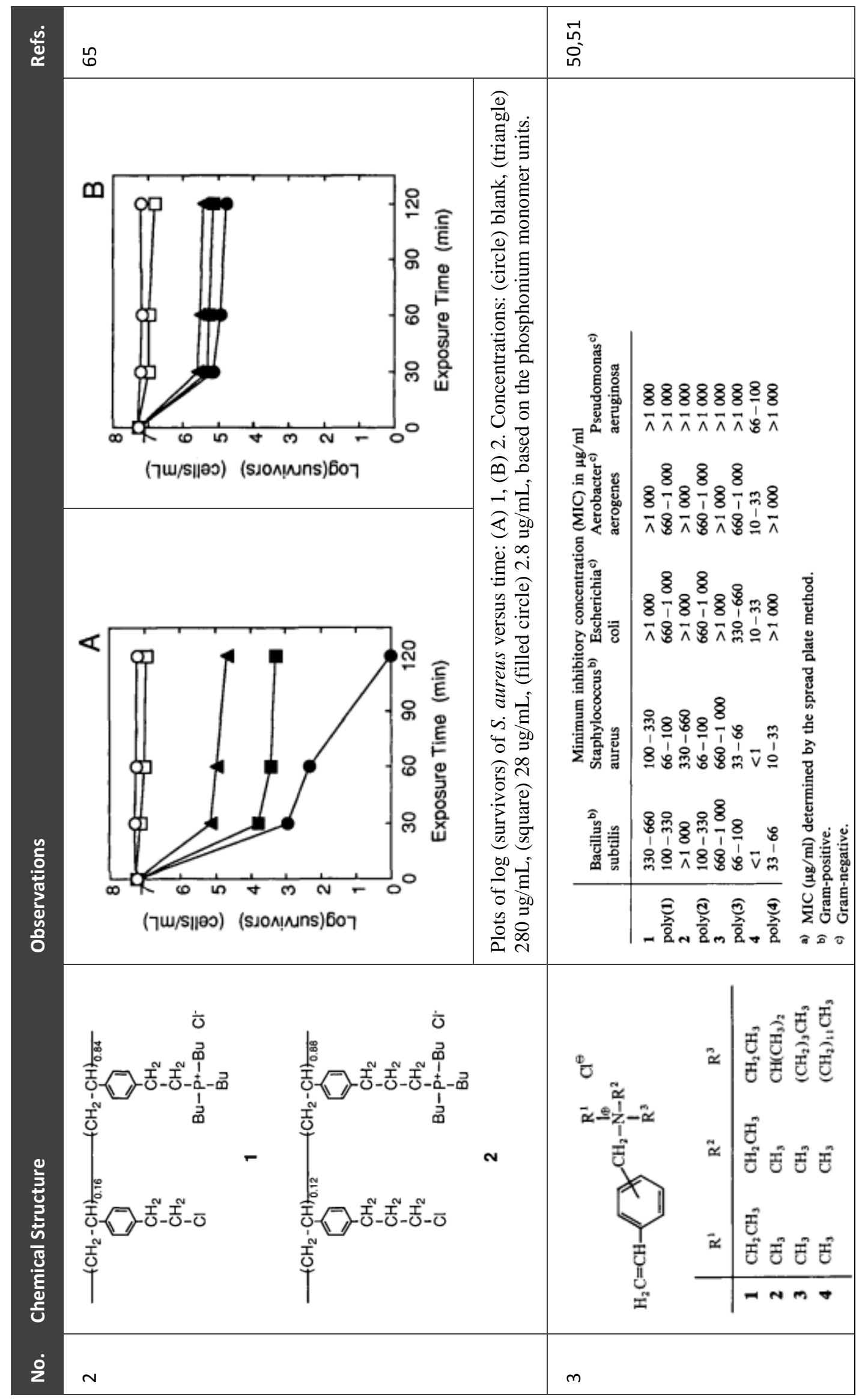




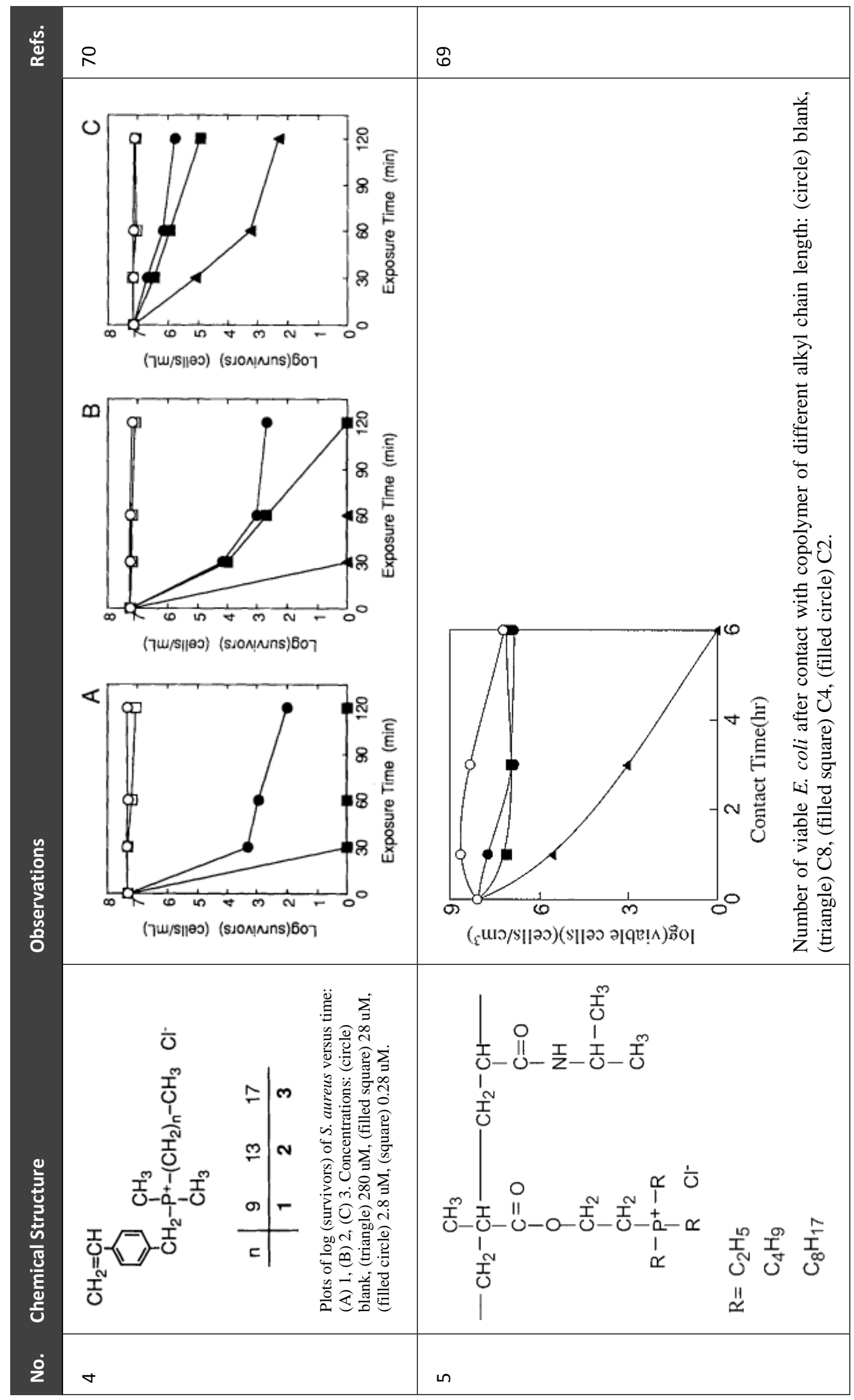


Polycationic antimicrobials with higher molecular weight have, in general, higher activity, especially when increasing molecular weight is accompanied by an increase in charge density as in dendrimers. It reaches maximum and then decreases as the diffusion-controlled process takes effect. The effect of counterion to antimicrobial activity depends on how easily it dissociates in solution. It follows that antimicrobial polymers with counterions that dissociate more readily are more active. That is why in many cases, quaternization was performed with bromide or chloride, which are well known to dissociate freely in the water.

The effect of alkyl chain length to antimicrobial activity is rather complex. When the active species is in and part of the main chain, the antibacterial activity of the polymers increases with increasing spacer length. However, for polymeric biocides with cationic charge on the side-chain, the activity decreases as the side-chain length increases, which is due to stronger hydrophobic interaction between chains. Lastly, below the critical micelle concentration, the activity increases with the number of carbon atoms in the hydrophobic tail due to stronger interlocking with the hydrophobic membrane core of bacterial cells.

The conclusion that can be made at this point, for polymeric biocides in solution, is that chain length is critical for the design of an effective antimicrobial polymer. The importance of charge density has also been alluded to and will be discussed further for surface-bound antimicrobial polymers.

\section{Surface Bound Antimicrobial Polymers}

In the past decade, due to the ever-growing demand for healthy living, considerable research efforts were performed in the development of nonleaching surfaces capable of killing microorganisms on contact. Immobilization has the advantage of long-term stability and lower toxicity than that by leach- or release-based systems, which lose their capacity to kill over time and could contaminate the environment. $^{1,82}$ Additionally, the gradual decreasing level of released substance could provide a condition for the development of antimicrobial resistance. ${ }^{79}$ One of the first examples of such a surface was described in the early 1970 s by a group of researchers at Dow Corning Corporation. ${ }^{30,83}$ They treated 28 substrates, which includes many different natural and synthetic fibers, with 3(trimethoxysilyl)-propyldimethyloctadecyl ammonium chloride and reported that all the treated surfaces exhibited antimicrobial properties. Twentysix microorganisms were used in the test. They also asserted that these surfaces could withstand repeated washing, indicating the durability of the treatment.

Some relevant examples of antimicrobial polycations immobilized on different surfaces are presented in Table 3. While soluble compounds may be able to penetrate the cell envelope, surface-bound molecules are constrained by their molecular length and could only penetrate the cell membrane if they extended far enough away from the surface. In their study of the cationic antimicrobial peptide, Bagheri et al. ${ }^{81}$ and Haynie et al. ${ }^{80}$ found that immobilization reduces peptide activity by two orders of magnitude.

It has been reported recently that for Gramnegative bacteria Escherichia coli, the thickness of the cell envelope is $46 \mathrm{~nm}$, which includes plasma membrane, periplasmic space, peptidoglycan, and outer membrane from inside out ${ }^{84}$ (see Figure 11). For Gram-positive bacteria Bacillus subtilis the thickness was found to be $45-55 \mathrm{~nm}^{85}$; it lacks an outer membrane but has thicker peptidoglycan. In order to effectively penetrate the cytoplasmic membrane and kill the cells, one possible solution would be to link the antimicrobial agent to a long, flexible polymeric chain anchored covalently to the surface of the material. In this regard, Tiller et al. ${ }^{18}$ found that shorter polymer chains of poly(vinyl- Nalkylpyridinium bromide) (PVP) immobilized on $\mathrm{NH}_{2}$-glass slide are significantly less effective than those with higher molecular weight (62\% as opposed to $94 \%$ for 60,000 and $160,000 \mathrm{~g} / \mathrm{mol}$ respectively).
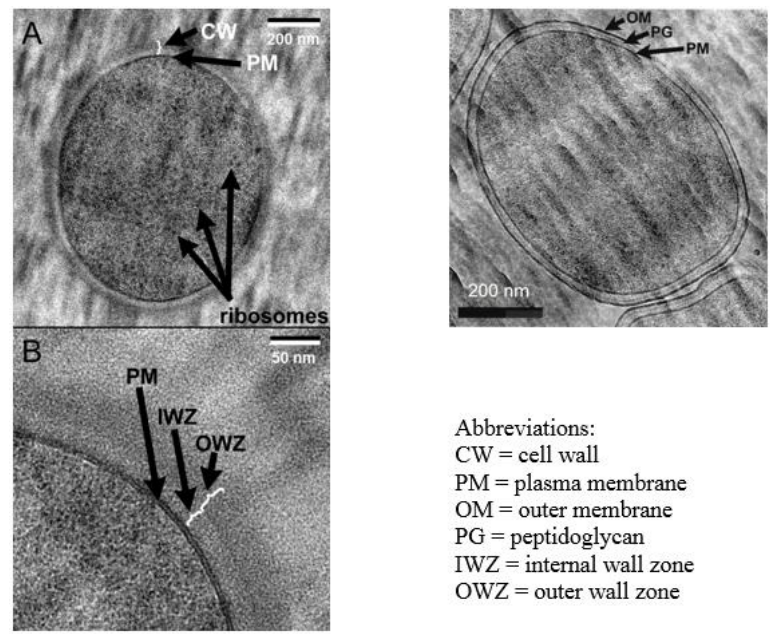

$$
\begin{aligned}
& \text { Abbreviations: } \\
& \mathrm{CW}=\text { cell wall } \\
& \mathrm{PM}=\text { plasma membrane } \\
& \mathrm{OM}=\text { outer membrane } \\
& \mathrm{PG}=\text { peptidoglycan } \\
& \mathrm{IWZ}=\text { internal wall zone } \\
& \mathrm{OWZ}=\text { outer wall zone }
\end{aligned}
$$

Figure 11. Cross-sections of frozen-hydrated $B$. subtilis 168 (left) and $E$. coli K-12 (right) obtained by cryo-TEM showing the structure of cell envelope ${ }^{84,85}$. 


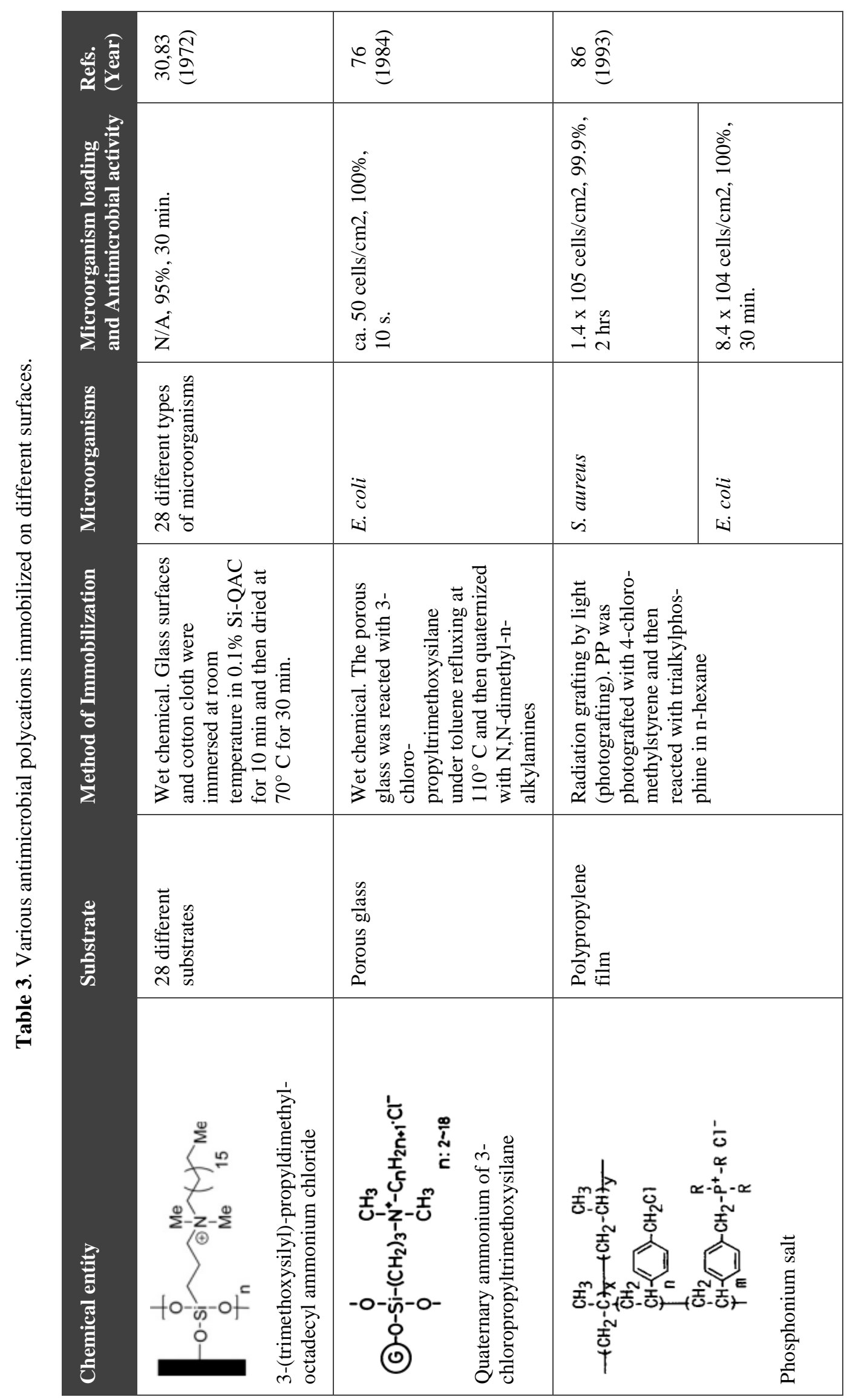




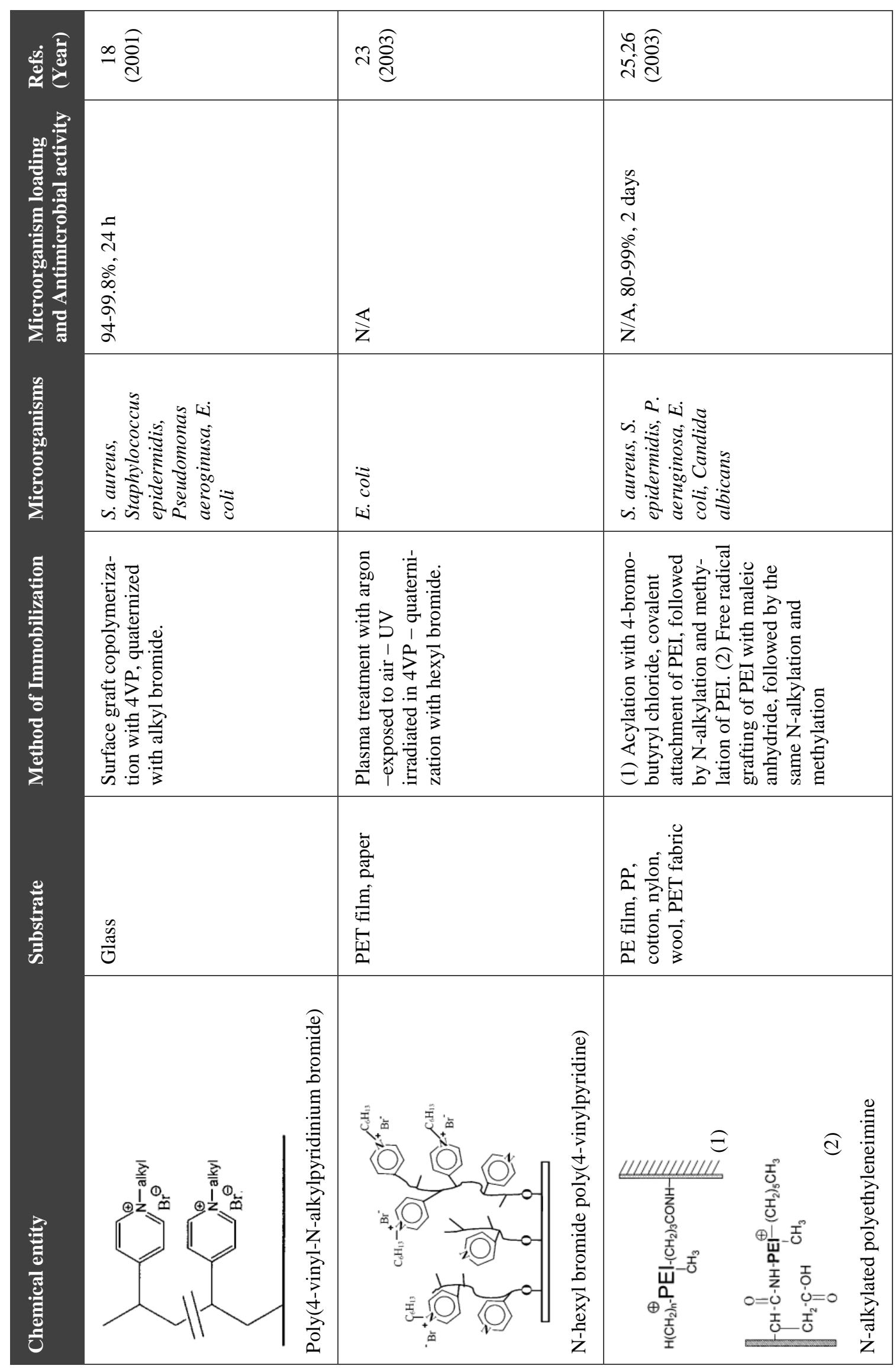


Table 4. Bactericidal activity of polyethyleneimine immobilized on cotton as a function of molecular weight. ${ }^{24}$

\begin{tabular}{cccc}
\hline \multirow{2}{*}{$\begin{array}{c}\text { Molecular weight } \\
\text { of PEI (kDa) }\end{array}$} & $\begin{array}{c}\text { Regular } \\
\text { wash }^{\mathbf{b}}\end{array}$ & $\begin{array}{c}\text { First } \\
\text { exhaustive wash }\end{array}$ & $\begin{array}{c}\text { Second } \\
\text { exhaustive wash }\end{array}$ \\
\hline 750 & $98 \pm 1$ & $98 \pm 1$ & $95 \pm 3$ \\
25 & $83 \pm 3$ & $75 \pm 11$ & $70 \pm 6$ \\
2 & $53 \pm 17$ & $35 \pm 15$ & $37 \pm 8$ \\
0.8 & $58 \pm 10$ & $24 \pm 4$ & $19 \pm 13$ \\
\hline
\end{tabular}

${ }^{\mathrm{b}}$ Consisted of washing with methanol and distilled water.

${ }^{\mathrm{c}}$ Consisted of additional stirring in soapy water at $55^{\circ} \mathrm{C}$ overnight, followed by thorough rinsing with distilled water.

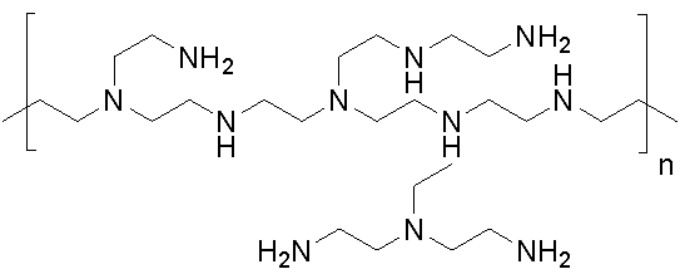

Figure 12. Polyethyleneimine

This is further substantiated by Lin et al. ${ }^{24}$ with different unrelated polycation, polyethyleneimine (PEI) (sixth row in Table 3 and Figure 12), confirming the generality of the conception. To reach a potency of $98 \%$ against airborne $S$. aureus, $750 \mathrm{kDa}$ PEI was necessary (Table 4), which was estimated to be approximately $6 \mu \mathrm{m}$ in length when fully extended ${ }^{24}$. It was more than enough to penetrate even the whole bacterial cell, which is typically in the order of $1-2 \mu \mathrm{m}$. The 25,2 , and $0.8 \mathrm{kDa}$ PEI in Table 4 is approximately $0.2,0.02$, and $0.007 \mu \mathrm{m}$ in length, respectively. The activity dropped significantly from $98 \%$ to $83 \%$, even when the polymer is believed to be long enough to penetrate the membrane $(0.2 \mu \mathrm{m}=200 \mathrm{~nm})$. It is not yet clear if there is any upper limit of molecular weight just as the case with antimicrobial polymers in solution (for example, see Refs 60 and 67).

This pattern was echoed by Haldar et al. ${ }^{32}$ when testing the virucidal efficacy of branched N,Ndodecyl methyl-PEI coating with varying molecular weights. The study found $750-\mathrm{kDa}$ PEI to have $100 \%$ virucidal activity after 10 minutes of exposure. The efficacy decreased to $98 \pm 0.4 \%$ and $97 \pm 0.2 \%$ when the molecular weight used was $25 \mathrm{kDa}$ and 2 $\mathrm{kDa}$, respectively.

Furthermore, Tiller et al. ${ }^{18}$ also showed that the efficacy of biocidal action was greatly affected by the number of carbons in the fatty alkyl chain attached to the $\mathrm{N}$ atom in the pyridinium groups. As seen in Figure 13, propylated (C3), butylated (C4), hexylated (C6), and octylated (C8) immobilized PVP chains were noticeably effective in reducing the number of viable bacterial cells (S. aureus), with hexyl-PVP being the most effective. In contrast, the immobilized PVP N-alkylated by decyl (C10) through hexadecyl (C16) bromides, as well as the non-alkylated chains, were ineffective. For nonalkylated bound PVP and those modified with longer alkyl moieties, hydrophobic interactions were predominant. They caused the bound polymer chains to adhere to each other creating hindrance for the adsorption of cationic species on the bacterial cell surface. However, for those with shorter alkyl chain (C3-C8), the hydrophobic interactions were not strong enough to overcome the electrostatic repulsion so that the chains were separated from each other, giving more access to the quaternary pyridinium groups in the polymer. The interactions are illustrated in the schematic depiction of the endgrafted polyelectrolyte on a substrate shown in Figure 13. The extent of chains separation, and thus their conformation, apparently depends on the interplay between hydrophobic interactions and electrostatic repulsion. In order that the chains extend as individual entities, there must be an optimum balance between the two forces. The balance can be accomplished by fine-tuning the length of hydrophobic chains with respect to charge and hydrophobicity. ${ }^{28}$

The same observation was reported by Lin et al. ${ }^{26}$ with PEI: bactericidal activity of $\mathrm{N}$-alkylated PEI increased with the number of carbon atoms in hydrophobic chains and reached its maximum with hexyl (Table 5 and Figure 14). Interestingly, when the positive charge of ammonium groups in the polymer was raised by subsequent methylation, and thus increased the electronic repulsion between chains bearing cationic groups, the activity pattern changed from the familiar bell-shaped curve to an Scurve (compare with Figure 4). Bactericidal activity still slowly increased even for dodecyl (C12) and octadecyl (C18).

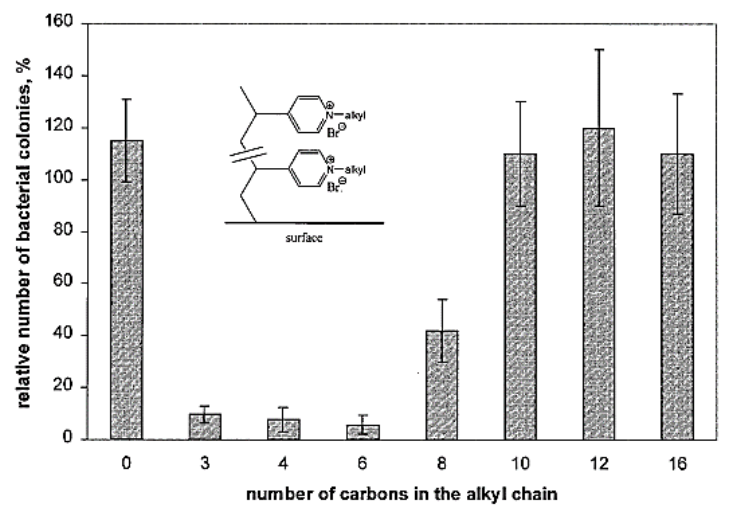




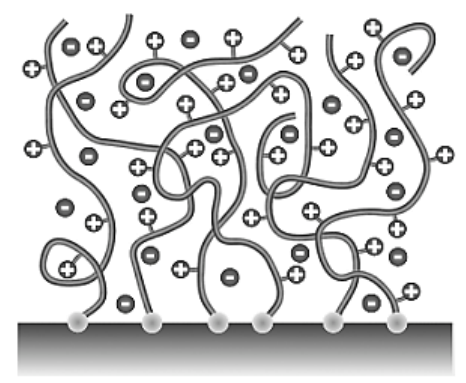

Figure 13. Effect of N-alkylation to the antimicrobial activity of polyvinyl pyridine against $S$. aureus (106 cells $/ \mathrm{mL}){ }^{18}$

Table 5. Effect of alkyl chain length and degree of positive charge to the antimicrobial activity of $N$-alkylated-PEI immobilized on glass surface against $S$. aureus. ${ }^{26}$

\begin{tabular}{|c|c|c|c|}
\hline \multicolumn{2}{|c|}{ alkylation } & \multirow{2}{*}{$\begin{array}{c}\text { quaternary } \\
\text { amino group } \\
\text { density }\left(\mathrm{nmol} / \mathrm{cm}^{2}\right)\end{array}$} & \multirow[b]{2}{*}{$\begin{array}{r}\text { bactericidal } \\
\text { efficiency (\%) }\end{array}$} \\
\hline $\begin{array}{l}\text { alkyl } \\
\text { chain }\end{array}$ & $\begin{array}{l}\text { subsequent } \\
\text { methylation }\end{array}$ & & \\
\hline none & no & $\sim 0$ & $14 \pm 8$ \\
\hline methyl & n.a. & $10.2 \pm 3.0$ & $18 \pm 20$ \\
\hline ethyl & no & $9.4 \pm 3.9$ & $15 \pm 16$ \\
\hline butyl & no & $6.9 \pm 2.0$ & $62 \pm 16$ \\
\hline hexyl & no & $6.1 \pm 2.4$ & $80 \pm 7$ \\
\hline dodecyl & no & $3.3 \pm 1.2$ & $66 \pm 13$ \\
\hline octadecyl & no & $1.1 \pm 0.6$ & $44 \pm 22$ \\
\hline ethyl & yes & $9.2 \pm 3.5$ & $22 \pm 15$ \\
\hline butyl & yes & $7.7 \pm 2.7$ & $56 \pm 13$ \\
\hline hexyl & yes & $6.8 \pm 1.9$ & $90 \pm 5$ \\
\hline dodecyl & yes & $4.8 \pm 1.5$ & $92 \pm 4$ \\
\hline octadecyl & yes & $4.2 \pm 2.1$ & $93 \pm 5$ \\
\hline
\end{tabular}

An elegant experiment conducted by Lin gave further highlights on the importance of positive charge. In addition to N-alkylation, immobilized PEI was either acylated or carboxyalkylated (the last two routes in Figure 15) to give neutral charge or zwitterionic polymer while keeping the hydrophobicity roughly the same. As expected, the two polymers were reported non-bactericidal. In the absence of a positive charge, there is no electrostatic repulsion between the polymer chains so that they collapse or become entangled to each other, hence reducing their ability to penetrate the cell membrane. Moreover, in neutral and zwitterionic polymers, there is no electrostatic interaction with negatively charged bacterial cells. A general strategy for creating an effective antimicrobial surface through immobilized polycation may thus far be concluded as follows: (1) long polymer chains (high enough molecular weight), (2) optimum length of hydrophobic chains, and (3) positive charge.

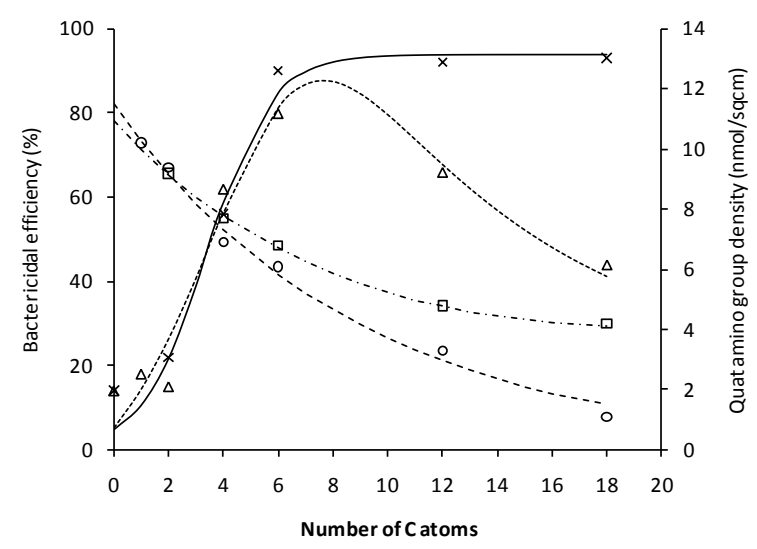

Figure 14. Bactericidal efficiency $(\triangle x=$ alkylatedPEI, $\times=$ alkylated-methylated-PEI) against $S$. aureus and density of quaternary ammonium group $(\mathrm{O}=$ alkylated-PEI, $\square=$ alkylatedmethylated-PEI) of PEI immobilized on the glass. From Table.

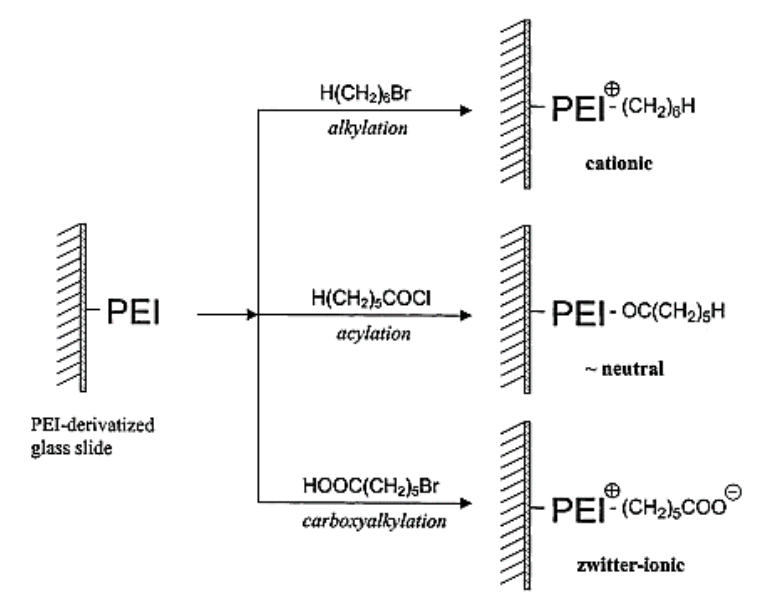

Figure 15. PEI was alkylated with hexyl bromide to produce cationic charges in the polymer, hexanoyl chloride and $\mathrm{N}$-alkylated with 6-bromohexanoic acid to give neutral and zwitterionic materials respectively. ${ }^{26}$

From the understanding of the roles played by each of the above three elements and their interrelationship, it becomes clear that an effective biocidal cationic surface must require high graft density and charge density. Recently, Kugler et al. ${ }^{19}$ and Murata et al. ${ }^{87}$, in their study with PVP and poly2-(dimethylammonium) ethyl methacrylate bromide respectively, showed the existence of a charge density threshold that is required to induce quick bacterial death upon adsorption (Figure 16). They have both come to an interestingly concurrent result that the most effective biocidal surfaces have charge densities in the proximity of $10^{15} \mathrm{~N}^{+} / \mathrm{cm}^{2}$, which is remarkably in accord with the surface charge of bacterial cells. The measurements for E. coli, according to Murata, ${ }^{87}$ are between $5 \times 10^{14}$ and $5 \times 10^{15} / \mathrm{cm}^{2}$ depending on their growth stage. 
Similar observation, interestingly, was also reported by Bagheri et al. ${ }^{81}$ with cationic antimicrobial peptide and E. coli.

High charge density can be accomplished on a substrate by having a high grafting density of polymer bearing cationic groups. When high grafting density cannot be attained, it can also be realized by using very long chains because longer polymer chains carry more cationic species. In this regard, Murata ${ }^{87}$ pointed out that short chains with high grafting density and long chains with low grafting density were equally effective as long as they have accessible charge density higher than $5 \times 10^{15} \mathrm{~N}^{+} / \mathrm{cm}^{2}$. However, it must be remembered that hydrophobic interactions between polymer chains and the propensity of the chains to the coil may hinder access. Unless the chains are extended and free from entanglement, the positive charge in the polymer would still be less accessible. Without any external force, this would require that grafting is sufficiently dense that the polymer chains are crowded and forced to stretch away from the surface in extended fashion to avoid overlapping. ${ }^{81}$

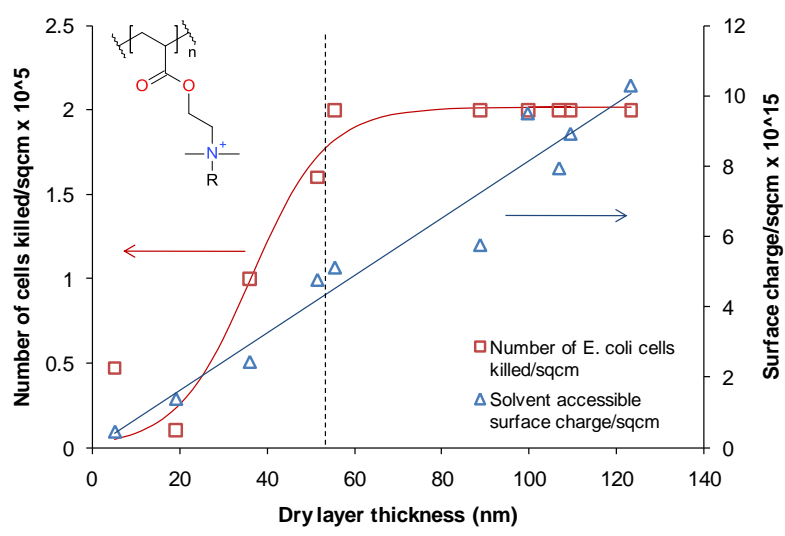

Figure 16. The effect of surface charge density to the antimicrobial activity of end-grafted poly-2-(dimethylammonium) ethyl methacrylate bromide against $E$. coli showing the existence of charge density threshold. The substrate surface was incubated with $2.0 \times 10^{5}$ cells $/ \mathrm{cm}^{2}$. (Adapted from Ref. 87).

The above-cited finding not only strengthens the importance of charge density but also indicates the existence of an alternative mechanism. As shown previously by Tiller et al. ${ }^{18}$ and Lin et al., ${ }^{24}$ a long polymer is required for an effective polycationic antimicrobial so that it penetrates bacterial cells and thereby disrupts the membrane much like a needle bursting a balloon. However, based on the observation on the existence of charge density threshold, which coincides with the value of the surface charge of bacterial cells, Kugler ${ }^{19}$ proposed that alternative mechanisms based on electrostatic interaction, i.e., charge-transfer mechanism, might take place. Upon adsorption on a cationic solid substrate, the electrostatic compensation of the negative charges of the bacterial envelope is taken over by the cationic charges of the substrate, hence releasing the natural counterions of the bacteria $\left(\mathrm{Mg}^{2+}\right.$ and $\left.\mathrm{Ca}^{2+}\right)$. These divalent counterions serve to stabilize the outer membrane by neutralizing and bridging the phosphate groups of the lipopolysaccharide molecules, which otherwise would repel each other. Their removal from the bacteria during adsorption on charged surface destabilizes the outer membrane leading to disruption of the bacterial envelope and nonviability. That may also explain, as pointed out by Murata, ${ }^{87}$ why surface bound 3-(trimethoxysilyl)propyldimethyl-octadecyl ammonium chloride, for example, is highly effective, despite the fact that it is only a monolayer thick.

According to Ravikumar et al., ${ }^{88}$ the mechanism by which antimicrobial polymers kill cells is much more likely dependent upon the physical form that they take. By comparing the antimicrobial activity of soluble and insoluble derivatives of poly(2-dimethylaminoethyl methacrylate), they hypothesized that soluble polymers are more likely to be able to penetrate cell walls and membranes, whereas surface-bound ones are more likely limited to a charge-transfer mechanism. ${ }^{88}$

A closer look at surface-bound antimicrobials reveals the problem of cleaning. Dead bacterial cells that accumulate on the cationic surfaces not only block the antimicrobial functional groups ${ }^{89}$ but also provide nutrients for cells that enter the system later, leading to rapid growth of biomass. ${ }^{36}$ Thus, adsorption of bacteria on biocidal cationic surfaces might reduce their potency over time. Recently, an interesting study ${ }^{89}$ reported a switchable polycation, poly(N,N-dimethyl-N-(ethoxycarbonylethyl)-N-[2'(methacryloyloxy) ethyl]-ammonium bromide) (Figure 17), that integrates antimicrobial and nonfouling properties. After killing bacteria, the polymer switches to a zwitterionic (see Figure 15) imparting nonfouling surface that releases dead bacterial cells upon hydrolysis. Much earlier on, Kanazawa ${ }^{86}$ described that the inactivated cationic surface of a phosphonium salt, which was due to the accumulation of dead cells, can be regenerated by simple washing with ethanol and sodium hydroxide solution.

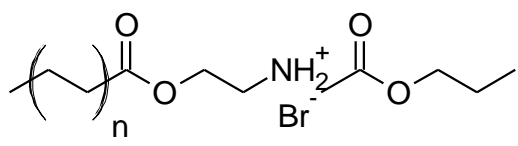

Figure 17. Switchable antimicrobial - nonfouling polymer, poly(N,N-dimethyl-N(ethoxycarbonylethyl) - $\mathrm{N}-[2$ (methacryloyl-oxy)ethyl]-ammonium bromide) $)^{89}$. 


\section{CONCLUSION}

There is more than one way to classify antimicrobials. They can be grouped based on their chemical structure, mechanisms of action, or based on their modes of actions. For each group of antimicrobials, both external and internal factors affect the efficacy and activity against microbes. The physical environment, the nature of the organism, and the resistance of the organism against antimicrobial agents are several of the external factors at play. The internal factors that affect antimicrobial efficacy are identified as molecular weight, spacer length between the active site and polymer, hydrophilic-lipophilic balance (HLB), the nature of counterion, and the location of the active component relative to the polymer backbone.

Generally, bacteria and viruses have a negative charge, while cationic micro biocides have a positive charge. This allows the microbicide to be adsorped, diffuse, and bind to the microbe's surface, ultimately disrupting the outer membrane. Polycations, carrying larger charge density than monomeric cations, are more likely to be adsorbed by the membrane of microbes. A correlation of molecular weight and biocidal activity has been observed both in polymeric and dendritic biocides. However, dendritic biocides are overall more effective than both polymeric and monomeric biocides due to the higher charge density on its surface.

A similar principle was observed when comparing the counterions of different polymers. A higher dissociation constant of a polymer's counter anion allows the cation to be available for action. Thus the type of counter anion is important in determining the strength of a biocide because it determines the dissociation constant.

The relationship between spacer length and antibacterial activity has been shown to be dependent on the location of the active species. The antibacterial activity of the polymers positively correlates with spacer length when the active site is a part of the main chain. On the other hand, antibacterial activity decreases with longer spacer length in polymeric biocides with cationic charges on the side chain.

Immobilization of surface-bound antimicrobial polymers was developed to address the concern of leaching. Immobilization can prolong the stability of the microbial activity and also protect against environmental contamination of free-floating antimicrobial actives. Based on the above discussion and the available data presented in the literature cited in this review, the general approach for creating effective biocidal cationic surfaces that kill microbes on contact can be outlined as follows: (1) long polymer chains (high enough molecular weight), (3) optimum length of hydrophobic chains, and (3) high charge density. It can be added that the surface charge density is the critical element. For a concluding remark, it is also important to distinguish between killing and cleaning, because killing by biocides does not always mean cleaning afterward. It seems that a new platform in the development of cationic biocidal surfaces must be considered, that is, antimicrobial and self-removal of dead cells.

\section{REFERENCES}

1. Kenawy, E.-R., Worley, S. D. \& Broughton, R. The Chemistry and Applications of Antimicrobial Polymers: A State-of-the-Art Review. Biomacromolecules 8, 1359-1384 (2007).

2. Appendini, P. \& Hotchkiss, J. H. Surface modification of poly(styrene) by the attachment of an antimicrobial peptide. J. Appl. Polym. Sci. 81, 609-616 (2001).

3. Batich, C. D., Mast, B. A., Olderman, G. M., Schultz, G. \& Lerner, D. S. Intrinsically bactericidal absorbent dressing and method of fabrication.

4. Schierholz, J. M. \& Beuth, J. Implant infections: a haven for opportunistic bacteria. J. Hosp. Infect. 49, 87-93 (2001).

5. Comstock, K., Farrell, D., Godwin, C. \& Xi, Y. From Hydrocarbons to Carbohydrates: Food Packaging of the Future.

6. Suppakul, P., Miltz, J., Sonneveld, K. \& Bigger, S. W. Active Packaging Technologies with an Emphasis on Antimicrobial Packaging and its Applications. J. Food Sci. 68, 408-420 (2003).

7. Persico, P. et al. Nanocomposite polymer films containing carvacrol for antimicrobial active packaging. Polym. Eng. Sci. 49, 1447-1455 (2009).

8. Bauer, T. M., Ofner, E., Just, H. M., Just, H. \& Daschner, F. D. An epidemiological study assessing the relative importance of airborne and direct contact transmission of microorganisms in a medical intensive care unit. J. Hosp. Infect. 15, 301-309 (1990).

9. WHO Timeline - COVID-19. Available at: https://www.who.int/news-room/detail/27-042020-who-timeline---covid-

19?gclid=CjwKCAjwxLH3BRApEiwAqX9arZ JXVC7K6rsrNCXTaQSx5Ce_i9_TWErACnnT hZgO9HNkdgl_SrKy2xoCHZcQAvD_BwE.

Accessed on 21 June 2020. (Accessed: 24th June 2020)

10. Modes of transmission of virus causing COVID19: implications for IPC precaution recommendations. Available at: https://www.who.int/news- 
room/commentaries/detail/modes-of-

transmission-of-virus-causing-covid-19-

implications-for-ipc-precaution-

recommendations. (Accessed: 24th June 2020)

11. Ng, K. et al. COVID-19 and the Risk to Health Care Workers: A Case Report. Ann. Intern. Med. 172, 766-767 (2020).

12. Feng, S. et al. Rational use of face masks in the COVID-19 pandemic. The Lancet Respiratory Medicine 8, 434-436 (2020).

13. Lai, M. Y. Y., Cheng, P. K. C. \& Lim, W. W. L. Survival of Severe Acute Respiratory Syndrome Coronavirus. Clin. Infect. Dis. 41, e67-e71 (2005).

14. Tashiro, T. Antibacterial and Bacterium Adsorbing Macromolecules. Macromol. Mater. Eng. 286, 63-87 (2001).

15. Muñoz-Bonilla, A. \& Fernández-García, M. Polymeric materials with antimicrobial activity. Progress in Polymer Science (Oxford) 37, 281339 (2012).

16. Siedenbiedel, F. \& Tiller, J. C. Antimicrobial Polymers in Solution and on Surfaces: Overview and Functional Principles. Polymers (Basel). 4, 46-71 (2012).

17. Santos, M. R. E. et al. Recent developments in antimicrobial polymers: A review. Materials $\mathbf{9}$, 599 (2016).

18. Tiller, J. C., Liao, C.-J., Lewis, K. \& Klibanov, A. M. Designing surfaces that kill bacteria on contact. Proc. Natl. Acad. Sci. U. S. A. 98, 59815985 (2001).

19. Kugler, R., Bouloussa, O. \& Rondelez, F. Evidence of a charge-density threshold for optimum efficiency of biocidal cationic surfaces. Microbiology 151, 1341-1348 (2005).

20. Lee, S. B. et al. Permanent, Nonleaching Antibacterial Surfaces. 1. Synthesis by Atom Transfer Radical Polymerization. Biomacromolecules 5, 877-882 (2004).

21. Thome, J., Holländer, A., Jaeger, W., Trick, I. \& Oehr, C. Ultrathin antibacterial polyammonium coatings on polymer surfaces. Surf. Coatings Technol. 174-175, 584-587

22. Thome, J., Holländer, A., Jaeger, W., Hahn, M. \& Trick, I. Antimikrobiell modifiziertes Substrat, Verfahren zu dessen Herstellung sowie dessen Verwendung.

23. Cen, L., Neoh, K. G. \& Kang, E. T. Surface Functionalization Technique for Conferring Antibacterial Properties to Polymeric and
Cellulosic Surfaces. Langmuir 19, 1029510303 (2003).

24. Lin, J., Qiu, S., Lewis, K. \& Klibanov, A. M. Mechanism of bactericidal and fungicidal activities of textiles covalently modified with alkylated polyethylenimine. Biotechnol. Bioeng. 83, 168-172 (2003).

25. Lin, J., Murthy, S. K., Olsen, B. D., Gleason, K. K. \& Klibanov, A. M. Making thin polymeric materials, including fabrics, microbicidal and also water-repellent. Biotechnol. Lett. 25, 16611665 (2003).

26. Lin, J., Qiu, S., Lewis, K. \& Klibanov, A. M. Bactericidal Properties of Flat Surfaces and Nanoparticles Derivatized with Alkylated Polyethylenimines. Biotechnol. Prog. 18, 10821086 (2002).

27. Lin, J., Tiller, J. C., Lee, S. B., Lewis, K. \& Klibanov, A. M. Insights into bactericidal action of surface-attached poly(vinyl-Nhexylpyridinium) chains. Biotechnol. Lett. 24, 801-805 (2002).

28. Tiller, J. C., Lee, S. B., Lewis, K. \& Klibanov, A. M. Polymer surfaces derivatized with poly(vinyl-N-hexylpyridinium) kill airborne and waterborne bacteria. Biotechnol. Bioeng. 79, 465-471 (2002)

29. Ignatova, M. et al. Synthesis of Copolymer Brushes Endowed with Adhesion to Stainless Steel Surfaces and Antibacterial Properties by Controlled Nitroxide-Mediated Radical Polymerization. Langmuir 20, 10718-10726 (2004).

30. Isquith, A. J., Abbott, E. A. \& Walters, P. A. Surface-Bonded Antimicrobial Activity of an Organosilicon Quaternary Ammonium Chloride. Appl. Environ. Microbiol. 24, 859863 (1972).

31. Isquith, A. J. \& McCollum, C. J. Surface kinetic test method for determining rate of kill by an antimicrobial solid. Appl. Environ. Microbiol. 36, 700-704 (1978).

32. Haldar, J., An, D., De Cienfuegos, L. Á., Chen, J. \& Klibanov, A. M. Polymeric coatings that inactivate both influenza virus and pathogenic bacteria. Proc. Natl. Acad. Sci. U. S. A. 103, 17667-17671 (2006).

33. Hernández, A. et al. Two known therapies could be useful as adjuvant therapy in critical patients infected by COVID-19. Rev. Española Anestesiol. y Reanim. (English Ed. 67, 245-252 (2020). 
34. Atwood, T. et al. Oxford Dictionary of Biochemistry and Molecular Biology. (Oxford University Press, USA, 2006).

35. Manivannan, G. Disinfection and Decontamination: Principles, Applications and Related Issues. (CRC Press, 2007).

36. Paulus, W. Directory of Microbicides for the Protection of Materials and Processes. (Springer, 2005).

37. Franklin, T. J. \& Snow, G. A. Biochemistry and Molecular Biology of Antimicrobial Drug Action. (Springer, 2005).

38. Singleton, P. \& Sainsbury, D. Dictionary of Microbiology \& Molecular Biology. (Wiley, 2006).

39. Kennedy, J. F. \& Tun, H. C. Active insolubilized antibiotics based on cellulose and cellulose carbonate. Antimicrob. Agents Chemother. 3, 575-579 (1973).

40. Buchenska, J. Polyamide fibers (PA6) with antibacterial properties. J. Appl. Polym. Sci. 61, 567-576 (1996).

41. Patel, H., Raval, D. A., Madamwar, D. \& Patel, S. R. Polymeric prodrug: Synthesis, release study and antimicrobial property of poly(styrene-co-maleic anhydride)-bound acriflavine. Die Angew. Makromol. Chemie 263, 25-30 (1998).

42. Patel, J. S., Patel, S. V., Talpada, N. P. \& Patel, H. A. Bioactive polymers: Synthesis, release study and antimicrobial properties of polymer bound Ampicillin. Die Angew. Makromol. Chemie 271, 24-27 (1999).

43. Moore, S. L. \& Payne, D. N. Type of Antimicrobial Agents. in 8-97 (WileyBlackwell, 2004).

44. Chapman, J. S. Biocide resistance mechanisms. Int. Biodeterior. Biodegradation 51, 133-138 (2003).

45. Ren, X. et al. Antimicrobial efficacy and light stability of $\mathrm{N}$-halamine siloxanes bound to cotton. Cellulose 15, 593-598 (2008).

46. Gottardi, W. \& Nagl, M. Chlorine covers on living bacteria: the initial step in antimicrobial action of active chlorine compounds. $J$. Antimicrob. Chemother. 55, 475-482 (2005).

47. Kim, J., Pitts, B., Stewart, P. S., Camper, A. \& Yoon, J. Comparison of the Antimicrobial Effects of Chlorine, Silver Ion, and Tobramycin on Biofilm. Antimicrob. Agents Chemother. 52, 1446-1453 (2008).
48. Dukan, S. \& Touati, D. Hypochlorous acid stress in Escherichia coli: resistance, DNA damage, and comparison with hydrogen peroxide stress. J. Bacteriol. 178, 6145-6150 (1996).

49. Dukan, S., Belkin, S. \& Touati, D. Reactive Oxygen Species Are Partially Involved in the Bacteriocidal Action of Hypochlorous Acid. Arch. Biochem. Biophys. 367, 311-316 (1999).

50. Liang, J. et al. Fabric Treated with Antimicrobial N-Halamine Epoxides. Ind. Eng. Chem. Res. 46, 6425-6429 (2007).

51. Rosas-Ledesma, P. et al. Antimicrobial efficacy in vivo of a new formulation of 2-butanone peroxide in n-propanol: comparison with commercial products in a cross-over trial. $J$. Hosp. Infect. 71, 223-227 (2009).

52. Wang, X. \& Zhao, X. Contribution of Oxidative Damage to Antimicrobial Lethality. Antimicrob. Agents Chemother. 53, 1395-1402 (2009).

53. Napimoga, M. H., de Oliveira, R., Reis, A. F., Gonçalves, R. B. \& Giannini, M. In vitro antimicrobial activity of peroxide-based bleaching agents. Quintessence Int. (Berlin, Ger. 1985) 38, e329-333 (2007).

54. Clapp, P. A., Davies, M. J., French, M. S. \& Gilbert, B. C. The bactericidal action of peroxides; an EPR spin-trapping study. Free Radic. Res. 21, 147-167 (1994).

55. Sun, G. \& Worley, S. Halamine Chemistry and its Applications in Biocidal Textiles and Polymers. in 81-89 (2006).

56. Schindler, W. D. \& Hauser, P. J. Chemical Finishing of Textiles. (CRC, 2004).

57. Factors Influencing the Efficacy of Antimicrobial. in (ed. Russell, A. D.) 98-127 (Wiley-Blackwell, 2004).

58. Ikeda, T. \& Tazuke, S. Biologically active polycations: Antimicrobial activities of Poly[trialkyl(vinylbenzyl)ammonium chloride]type polycations. Die Makromol. Chemie, Rapid Commun. 4, 459-461 (1983).

59. Ikeda, T., Tazuke, S. \& Suzuki, Y. Biologically active polycations, 4. Synthesis and antimicrobial activity of poly(trialkylvinylbenzylammonium chloride)s. Die Makromol. Chemie 185, 869-876 (1984).

60. Ikeda, T., Hirayama, H., Yamaguchi, H., Tazuke, S. \& Watanabe, M. Polycationic biocides with pendant active groups: molecular weight dependence of antibacterial activity. Antimicrob. Agents Chemother. 30, 132-6 
(1986).

61. Ikeda, T., Yamaguchi, H. \& Tazuke, S. Molecular Weight Dependence of Antibacterial Activity in Cationic Disinfectants. J. Bioact. Compat. Polym. 5, 31-41 (1990).

62. Kanazawa, A., Ikeda, T. \& Endo, T. Polymeric phosphonium salts as a novel class of cationic biocides. IV. Synthesis and antibacterial activity of polymers with phosphonium salts in the main chain. J. Polym. Sci. Part A Polym. Chem. 31, 3031-3038 (1993).

63. Kanazawa, A., Ikeda, T. \& Endo, T. Polymeric phosphonium salts as a novel class of cationic biocides. II. Effects of counter anion and molecular weight on antibacterial activity of polymeric phosphonium salts. J. Polym. Sci. Part A Polym. Chem. 31, 1441-1447 (1993).

64. Zheng, L.-Y. \& Zhu, J.-F. Study on antimicrobial activity of chitosan with different molecular weights. Carbohydr. Polym. 54, 527530 (2003).

65. Gilbert, P. \& Moore, L. E. Cationic antiseptics: diversity of action under a common epithet. $J$. Appl. Microbiol. 99, 703-715 (2005).

66. Panarin, E. F., Solovskii, M. V., Zaikina, N. A. \& Afinogenov, G. E. Biological activity of cationic polyelectrolytes. Die Makromol. Chemie 9, 25-33 (1985).

67. Chen, C. Z. et al. Quaternary Ammonium Functionalized Poly(propylene imine) Dendrimers as Effective Antimicrobials: Structure-Activity Studies. Biomacromolecules 1, 473-480 (2000).

68. Russell, Hugo \& Ayliffe's Principles and Practice of Disinfection, Preservation \& Sterilization. (Wiley-Blackwell, 2004).

69. Eaton, P., Fernandes, J. C., Pereira, E., Pintado, M. E. \& Xavier Malcata, F. Atomic force microscopy study of the antibacterial effects of chitosans on Escherichia coli and Staphylococcus aureus. Ultramicroscopy 108, 1128-1134 (2008).

70. Tomalia, D. A. et al. A New Class of Polymers: Starburst-Dendritic Macromolocelues. Polym. J. 17, 117-132 (1985).

71. Kleszczynska, H., Sarapuk, J. \& RozyckaRoszak, B. The Role of Counterions in the Interaction of Some Cationic Surfactants with Model Membranes. Polish J. Environ. Stud. 7, 327-329 (1998).

72. Mynacik, D., Devinsky, F. \& Lacko, I. Influence of counterions on antimicrobial activity of quaternary ammonium salts. Eur. J. Pharm. Sci. 4, S191 (1996).

73. Kanazawa, A., Ikeda, T. \& Endo, T. Polymeric phosphonium salts as a novel class of cationic biocides. IX. Effect of side-chain length between main chain and active group on antibacterial activity. J. Polym. Sci. Part A Polym. Chem. 32, 1997-2001 (1994).

74. Kanazawa, A., Ikeda, T. \& Endo, T. A novel approach to mode of action of cationic biocides morphological effect on antibacterial activity. $J$. Appl. Microbiol. 78, 55-60 (1995).

75. Balgavý, P. \& Devínsky, F. Cut-off effects in biological activities of surfactants. Adv. Colloid Interface Sci. 66, 23-63 (1996).

76. Nakagawa, Y. et al. Disinfection of Water with Quaternary Ammonium Salts Insolubilized on a Porous Glass Surface. Appl. Environ. Microbiol. 47, 513-518 (1984)

77. Nonaka, T., Hua, L., Ogata, T. \& Kurihara, S. Synthesis of water-soluble thermosensitive polymers having phosphonium groups from methacryloyloxyethyl trialkyl phosphonium chlorides-N-isopropylacrylamide copolymers and their functions. J. Appl. Polym. Sci. 87, 386393 (2003).

78. Kanazawa, A., Ikeda, T. \& Endo, T. Polymeric phosphonium salts as a novel class of cationic biocides. VII. Synthesis and antibacterial activity of polymeric phosphonium salts and their model compounds containing long alkyl chains. J. Appl. Polym. Sci. 53, 1237-1244 (1994).

79. Lewis, K. \& Klibanov, A. M. Surpassing nature: rational design of sterile-surface materials. Trends Biotechnol. 23, 343-348 (2005).

80. Haynie, S., Crum, G. \& Doele, B. Antimicrobial activities of amphiphilic peptides covalently bonded to a water-insoluble resin. Antimicrob. Agents Chemother. 39, 301-307 (1995).

81. Bagheri, M., Beyermann, M. \& Dathe, M. Immobilization Reduces the Activity of Surface-Bound Cationic Antimicrobial Peptides with No Influence upon the Activity Spectrum. Antimicrob. Agents Chemother. 53, 1132-1141 (2009).

82. Huang, J. et al. Nonleaching Antibacterial Glass Surfaces via "Grafting Onto": The Effect of the Number of Quaternary Ammonium Groups on Biocidal Activity. Langmuir 24, 6785-6795 (2008).

83. Walters, P. A., Abbott, E. A. \& Isquith, A. J. 
Algicidal Activity of a Surface-Bonded Organosilicon Quaternary Ammonium Chloride. Appl. Environ. Microbiol. 25, 253256 (1973).

84. Matias, V. R. F., Al-Amoudi, A., Dubochet, J. \& Beveridge, T. J. Cryo-Transmission Electron Microscopy of Frozen-Hydrated Sections of Escherichia coli and Pseudomonas aeruginosa. J. Bacteriol. 185, 6112-6118 (2003).

85. Matias, V. R. F. \& Beveridge, T. J. Cryoelectron microscopy reveals native polymeric cell wall structure in Bacillus subtilis 168 and the existence of a periplasmic space. Mol. Microbiol. 56, 240-251 (2005).

86. Kanazawa, A., Ikeda, T. \& Endo, T. Polymeric phosphonium salts as a novel class of cationic biocides. III. Immobilization of phosphonium salts by surface photografting and antibacterial activity of the surface-treated polymer films. $J$. Polym. Sci. Part A Polym. Chem. 31, 1467-1472 (1993).

87. Murata, H., Koepsel, R. R., Matyjaszewski, K. \& Russell, A. J. Permanent, non-leaching antibacterial surfaces--2: How high density cationic surfaces kill bacterial cells. Biomaterials 28, 4870-4879 (2007).

88. Ravikumar, T., Murata, H., Koepsel, R. R. \& Russell, A. J. Surface-Active Antifungal Polyquaternary Amine. Biomacromolecules 7, 2762-2769 (2006).

89. Cheng, G., Xue, H., Zhang, Z., Chen, S. \& Jiang, S. A Switchable Biocompatible Polymer Surface with Self-Sterilizing and Nonfouling Capabilities. Angew. Chemie Int. Ed. 47, 88318834 (2008). 